\title{
Discovery of SHR1653, a Highly Potent and Selective OTR Antagonist with Improved Blood-Brain Barrier Penetration \\ Property
}

\author{
Xin Li, ${ }^{*}+$ Zhigao Zhang, ${ }^{+}$Yang Chen, ${ }^{+}$Hong Wan, ${ }^{+}$Jiakang Sun, ${ }^{+}$Bin Wang, ${ }^{+}$Bingqiang Feng, ${ }^{+}$ \\ Bing $\mathrm{Hu},{ }^{+}$Xingxing Shi, Jun Feng, Lei Zhang, ${ }^{+}$Feng He, ${ }^{+}$' Chang Bai, ${ }^{+}$Lianshan Zhang, \\ Weikang $\mathrm{Tao}^{+\boldsymbol{g}}$ \\ †Shanghai Hengrui Pharmaceutical CO., LTD., 279 Wenjing Road, Shanghai 200245, China \\ ${ }^{9}$ Chengdu Suncadia Medicine Co., LTD., 88 South Keyuan Road, Chengdu, Si Chuan 610000, China \\ †Jiangsu Hengrui Medicine CO., LTD., Lianyungang, Jiangsu 222047, China \\ *lix@shhrp.com
}

\section{List of Contents}

General Information

Synthetic procedure and characterization for key compounds---------------------------S3-S16

Spectrum of SHR1653 -S17-S20

Methods for in vitro, in vivo and pharmacokinectic studies-

$-\mathbf{S 2 1 - S 2 3}$

References $\mathbf{S 2 3}$ 


\section{General Information}

${ }^{1} \mathrm{H}$ and ${ }^{13} \mathrm{C}$ spectra were recorded on a bruker avance-400 NMR spectrometer $\left({ }^{1} \mathrm{H}: 400 \mathrm{MHz},{ }^{13} \mathrm{C}: 100\right.$ $\mathrm{MHz}$ ) using $\mathrm{CDCl}_{3}, \mathrm{CD}_{3} \mathrm{OD}$ or DMSO- $\mathrm{d}_{6}$ as a solvent and tetramethylsilane (TMS) as an internal standard. Chemical shift $(\delta)$ are reported in parts per million (ppm) relative to TMS $(\delta=0.00 \mathrm{ppm})$ and coupling constant $(J)$ are reported in Hertz $(\mathrm{Hz})$. Splitting patterns are indicated as follows: s, singlet; d, doublet; $\mathrm{t}$, triplet; $\mathrm{m}$, multiplet; brs, broad singlet. mass spectra were determined on a FINNIGAN LCQAd (ESI) spectrometer (Finnigan LCQ advantage MAX, Thermo). Products were purified by column chromatography(200-300 mesh, Yantai Huanghai), or prep-TLC (0.4-0.5 mm, GF-254, Liangchen Guiyuan). 


\section{Synthetic procedure and characterization for new compounds}

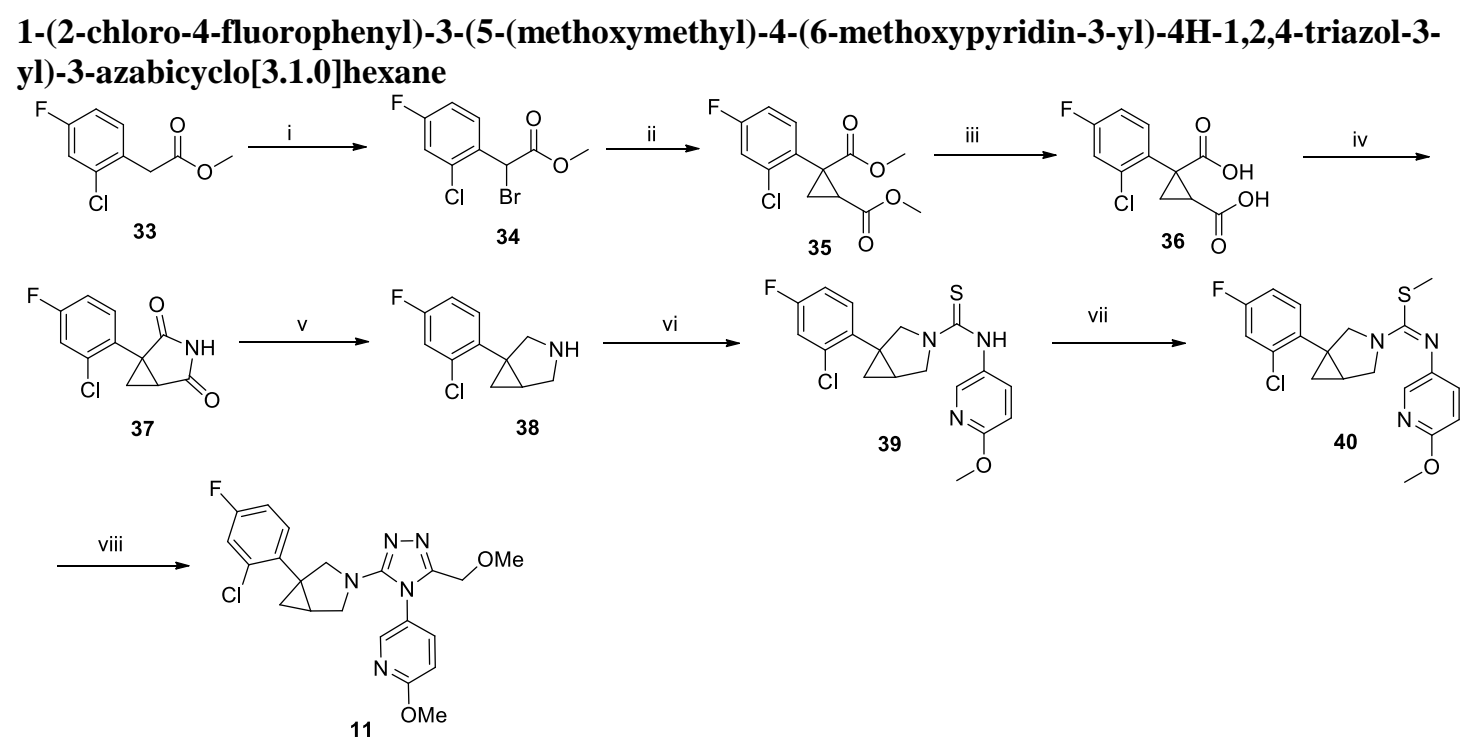

i:Methyl 2-(2-chloro-4-fluorophenyl)acetate 33 (2.4 g, $11.8 \mathrm{mmol}$ ) and $\mathrm{N}$-Bromosuccinimide ( $2.4 \mathrm{~g}, 13.5$ mmol) were dissolved in $\mathrm{CCl}_{4}(25 \mathrm{ml})$, followed by addition of one drop of $\mathrm{HBr}(40 \%)$. The reaction mixture were heated up to $78{ }^{\circ} \mathrm{C}$ and stirred for $18 \mathrm{~h}$. After the reaction temperature slowly decreased until room temperature, the mixture was filtered. The filtrate 34 (4.3 g) was then concentrated and applied into next step without further purification.

MS m/z (ESI): $\mathrm{C}_{9} \mathrm{H}_{7} \mathrm{BrClFO}_{2}[\mathrm{M}+\mathrm{H}]^{+} 280.9$, found 280.3 .

ii: crude product $34(4.3 \mathrm{~g})$ and methyl acrylate $(2.0 \mathrm{~mL}, 22 \mathrm{mmol})$ were added into ethyl ether/ethanol (20.4 mL, volume: 50/50) before the addition of the solution of $\mathrm{NaH}(720 \mathrm{mg}, 18 \mathrm{mmol}$ ) in ethyl ether/ethanol (50.5 mL, volume: 100/1). The reaction mixture was stirred for $23 \mathrm{~h}$, before the water $(80$ $\mathrm{mL}$ ) was added. The reaction mixture was then separated and the aqueous phase was extracted by ethyl acetate $(50 \mathrm{~mL} * 3)$. After the combined organic phase was concentrated under rotavapor, the crude dimethyl ester 35 ( $4.0 \mathrm{~g})$ was applied into next step without further purification.

MS m/z (ESI): $\mathrm{C}_{13} \mathrm{H}_{12} \mathrm{ClFO}_{4}$ : $[\mathrm{M}+\mathrm{H}]^{+}$287.0, found 287.3.

iii: Crude product 35 were dissolved in ethanol/water $(60 \mathrm{~mL}$, volume: $1 / 1)$ followed by the addition of $\mathrm{KOH}(3.0 \mathrm{~g}, 53.5 \mathrm{mmol})$. The reaction mixture was stirred at $65^{\circ} \mathrm{C}$ for $15 \mathrm{~h}$. The solution was added $\mathrm{HCl}$ ( $2 \mathrm{~N}$ aqueous solution) until the $\mathrm{pH}$ was $2-3$. The mixture was added ethyl acetate $(50 \mathrm{~mL})$ and separated. The aqueous phase was extracted by ethyl acetate $(50 \mathrm{~mL} * 3)$. After the combined organic phase was concentrated under rotavapor, the crude acid 36 (1.9 g) was utilized without further purification.

MS m/z (ESI): $\mathrm{C}_{11} \mathrm{H}_{8} \mathrm{ClFO}_{4}[\mathrm{M}-\mathrm{H}]^{-} 257.0$, found 257.2

iv: crude product 36 (1.9 g, $7.5 \mathrm{mmol})$ and carbamide $(1.35 \mathrm{~g}, 22.5 \mathrm{mmol})$ were dissolved in para-xylene $(20 \mathrm{~mL})$. The reaction mixture were stirred under $120^{\circ} \mathrm{C}$ for $18 \mathrm{~h}$. The solution were then concentrated under rotavapor. The product $\mathbf{3 7}(110 \mathrm{mg})$ was separated from the above residue with high-performance liquid chromatograph. Yield was $6.1 \%$.

MS m/z (ESI): $\mathrm{C}_{11} \mathrm{H}_{7} \mathrm{ClFNO}_{2}[\mathrm{M}+\mathrm{H}]^{+}: 240.0$, found 240.2 .

v: $37(100 \mathrm{mg}, 0.37 \mathrm{mmol})$ and $\mathrm{BH}_{3}(2.0 \mathrm{~mL}, 1 \mathrm{~N}$ THF solution $)$ were mixed in THF $(5.0 \mathrm{~mL})$. The reaction mixture was stirred for $15 \mathrm{~h}$ before heated up to $60^{\circ} \mathrm{C}$. After stirring $1 \mathrm{~h}$ under $60^{\circ} \mathrm{C}, \mathrm{HCl}(2.0$ 
$\mathrm{mL}, 6 \mathrm{~N}$ aqueous solution) was added. The reaction was stopped after $15 \mathrm{~min}$, and the THF was removed under reduced pressure. $\mathrm{pH}$ of solution was adjusted around 12 with $\mathrm{NaOH}$ ( $5 \mathrm{~N}$ aqueous solution). After stirring 15 mins, reaction was diluted with ethyl acetate $(20 \mathrm{~mL})$ and the aqueous phase was extracted by ethyl acetate $(20 \mathrm{~mL} * 3)$. The combined organic phase was washed by brine $\left(15 \mathrm{~mL}^{* 2}\right)$ and dried with $\mathrm{Na}_{2} \mathrm{SO}_{4}$. The solution was then concentrated under rotavapor to deliver crude amine $\mathbf{3 8}$ (90 mg), which was applied into next step without further purification.

$\mathrm{MS} \mathrm{m} / \mathrm{z}(\mathrm{ESI}): \mathrm{C}_{11} \mathrm{H}_{11} \mathrm{ClFN}[\mathrm{M}+\mathrm{H}]^{+}:$212.1, found 212.2.

vi: amine 38 (90 mg, $0.37 \mathrm{mmol})$ and 5-isothiocyanato-2-methoxypyridine (90 mg, $0.55 \mathrm{mmol})^{1}$ were dissolved in THF $(5.0 \mathrm{~mL})$. The reaction mixture was stirred for $18 \mathrm{~h}$ under $50{ }^{\circ} \mathrm{C}$. The solution was then concentrated under reduced pressure. The crude product $39(140 \mathrm{mg})$ in the residue was utilized without further purification.

$\mathrm{MS} \mathrm{m} / \mathrm{z}$ (ESI): $\mathrm{C}_{18} \mathrm{H}_{17} \mathrm{ClFN}_{3} \mathrm{OS}[\mathrm{M}+\mathrm{H}]^{+}: 378.1$, found 378.3 .

vii: crude product $39(140 \mathrm{mg}, 0.37 \mathrm{mmol})$ were dissolved in cooled THF $\left(10 \mathrm{~mL}, 0{ }^{\circ} \mathrm{C}\right)$ followed by addition of $\mathrm{KO}^{\mathrm{t}} \mathrm{Bu}(85 \mathrm{mg}, 0.74 \mathrm{mmol})$. The reaction mixture was stirred for $3 \mathrm{~h}$ before the addition of TsOMe (155 mg, $0.81 \mathrm{mmol})$. The reaction was allowed to slowly warm up and stirred for $15 \mathrm{~h}$. The reaction was stopped by ice water $(20 \mathrm{~mL})$ and separated. The aqueous phase was extracted by ethyl acetate $\left(30 \mathrm{~mL}^{*} 3\right)$. The combined organic phase was then washed by brine (20 mL*2), dry with $\mathrm{Na}_{2} \mathrm{SO}_{4}$ and concentrated under rotavapor. The product 40 (50 mg, yellow solid) was isolated through Prep-TLC. Yield is $34.4 \%$.

MS m/z (ESI): $\mathrm{C}_{19} \mathrm{H}_{19} \mathrm{ClFN}_{3} \mathrm{OS}[\mathrm{M}+\mathrm{H}]^{+}:$392.1, found 392.3.

viii: Compound 40 (50 mg, $0.17 \mathrm{mmol})$, 2-methoxyacetohydrazide ( $88 \mathrm{mg}, 0.85 \mathrm{mmol}$ ) were dissolved in THF $(5.0 \mathrm{~mL})$ followed by addition of two drops of trifluoroacetic acid. The reaction mixture was stirred for $2 \mathrm{~h}$ at $70{ }^{\circ} \mathrm{C}$. The solution was the concentrated under reduced pressure. The product $\mathbf{1 1}(8 \mathrm{mg}$, yellow solid) was isolated through Prep-TLC. Yield is $10.9 \%$.

HRMS m/z (ESI): $\mathrm{C}_{21} \mathrm{H}_{21} \mathrm{ClFN}_{5} \mathrm{O}_{2}[\mathrm{M}+\mathrm{H}]^{+}:$430.1441, found 430.1452.

${ }^{1} \mathrm{H} \mathrm{NMR}\left(400 \mathrm{MHz}, \mathrm{CDCl}_{3}\right): \delta 8.17(\mathrm{~s}, 1 \mathrm{H}), 7.56(\mathrm{~d}, 1 \mathrm{H}, J=8.8 \mathrm{~Hz}), 7.27(\mathrm{t}, 1 \mathrm{H}, J=6.28 \mathrm{~Hz}), 7.10(\mathrm{~d}, 1 \mathrm{H}$, $J=8.52 \mathrm{~Hz}), 6.91-6.88(\mathrm{~m}, 2 \mathrm{H}), 4.28(\mathrm{~s}, 2 \mathrm{H}), 4.01$ (s, 3H), 3.64 (d, 1H, J=9.52 Hz), 3.46 (d, 2H, $J=9.25$ $\mathrm{Hz}), 3.43$ (d, 1H, J=9.28 Hz), 3.28 (s, 3H), 1.73-1.70 (m, 1H), 1.01-0.98 (m, 2H).

${ }^{13} \mathrm{C}$ NMR (100 MHz, $\left.\mathrm{CDCl}_{3}\right)$ : 164.21, 162.87-160.36, 157.32, 149.34, 145.51, 137.50, 136.58-136.48, 133.28-133.23, 132.97-132.87, 124.66, 117.13-116.93, 114.01-113.81, 111.64, 63.76, 57.77, 54.91, $54.02,51.74,30.60,23.56,15.05$.

(1R,5S)-1-(2-chloro-4-fluorophenyl)-3-(5-(methoxymethyl)-4-(6-methoxypyridin-3-yl)-4H-1,2,4triazol-3-yl)-3-azabicyclo[3.1.0]hexane 

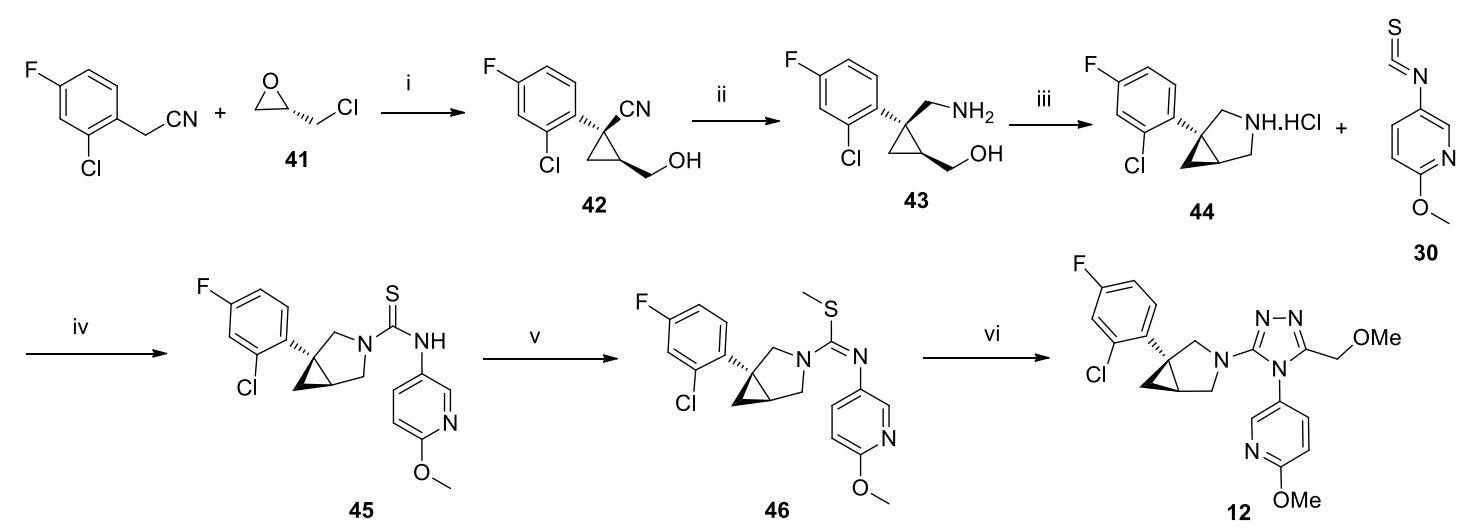

i: 3-chloro-4-fluorophenylacetonitrile $(1.0 \mathrm{~g}, 5.9 \mathrm{mmol})$ was dissolved in a cooled THF $(8.0 \mathrm{~mL})$ at -20 ${ }^{\circ} \mathrm{C}$, followed by slow addition of NaHMDS $(2.2 \mathrm{~g}, 11.8 \mathrm{mmol})$. The reaction was stirred for $30 \mathrm{~min}$ and $S$-epichlorohydrin 41 (600 mg, $6.49 \mathrm{mmol})$ was added. ${ }^{2}$ The reaction was allowed to slowly warm up to room temperature. After $3 \mathrm{~h}$, the reaction was stopped by $\mathrm{NH}_{4} \mathrm{Cl}(20 \mathrm{~mL}$, aqueous solution). The solution was then separated and aqueous phase was extracted by ethyl acetate $(50 \mathrm{~mL} * 3)$. The combined organic phase was then concentrated under reduced pressure. The crude product $\mathbf{4 2}(1.3 \mathrm{~g})$ was then applied to next step without further purification.

MS m/z (ESI): $\mathrm{C}_{11} \mathrm{H}_{9} \mathrm{ClFNO}[\mathrm{M}+\mathrm{H}]^{+}: 226.0$, found 226.3.

ii: $\mathrm{LiAH}_{4}(210 \mathrm{mg}, 5.5 \mathrm{mmol})$ was dissolved in cooled THF $(8.0 \mathrm{~mL})$ at $0{ }^{\circ} \mathrm{C}$. Crude cyanide $\mathbf{4 2}(500 \mathrm{mg}$, $2.22 \mathrm{mmol}$ ) was then slowly added. The reaction mixture warmed up to room temperature and was stirred for $15 \mathrm{~h}$. The solution was sequentially added water $(0.25 \mathrm{~mL}), \mathrm{NaOH}$ aqueous solution $(0.25 \mathrm{~mL}, 2 \mathrm{~N})$, water $(0.75 \mathrm{~mL})$. The mixture was filtrated and filtration was concentrated to afford crude aminol $\mathbf{4 3}$ (300 mg), which was directly applied into next step without further purification.

MS m/z (ESI): $\mathrm{C}_{11} \mathrm{H}_{13} \mathrm{ClFNO}[\mathrm{M}+\mathrm{H}]^{+}: 230.1$, found 230.3.

iii: 43 (505 mg, $2.2 \mathrm{mmol})$ was dissolved in cooled $\mathrm{CH}_{2} \mathrm{Cl}_{2}(8.0 \mathrm{~mL})$ at $0{ }^{\circ} \mathrm{C}$, thionyl chloride was slowly added (393 mg, $3.3 \mathrm{mmol}$ ). The reaction slowly warmed up and was stirred for $3 \mathrm{~h}$. The mixture was concentrated under reduced pressure to afford crude amine $\mathbf{4 4}$ (300 $\mathrm{mg}$ ), which was directly applied into next step without further purification.

MS m/z (ESI): $\mathrm{C}_{11} \mathrm{H}_{11} \mathrm{ClFN}[\mathrm{M}+\mathrm{H}]^{+}: 212.1$, found 212.2.

iv: 44 (233 mg, $1.1 \mathrm{mmol})$ and 5-isothiocyanato-2-methoxypyridine ( $366 \mathrm{mg}, 2.2 \mathrm{mmol})^{1}$ were dissolved in THF $(8.0 \mathrm{~mL})$. The reaction mixture was stirred for $3 \mathrm{~h}$. The solution was then concentrated under reduced pressure. The crude product $45(260 \mathrm{mg})$ in the residue was utilized without further purification. MS m/z (ESI): $\mathrm{C}_{18} \mathrm{H}_{17} \mathrm{ClFN}_{3} \mathrm{OS}[\mathrm{M}+\mathrm{H}]^{+}: 378.1$, found 378.3 .

v: 45 (416 mg, $1.1 \mathrm{mmol})$ were dissolved in cooled THF $\left(8.0 \mathrm{~mL}, 0^{\circ} \mathrm{C}\right)$ followed by addition of $\mathrm{KO}^{\mathrm{t}} \mathrm{Bu}$ ( $449 \mathrm{mg}$, $4.0 \mathrm{mmol}$ ). The reaction mixture was stirred for $1 \mathrm{hr}$ before the addition of TsOMe (410 mg, $2.2 \mathrm{mmol}$ ). The reaction was allowed to slowly warm up and stirred for $48 \mathrm{~h}$. The reaction was stopped by ice water $(20 \mathrm{~mL})$ and separated. The aqueous phase was extracted by ethyl acetate $(30 \mathrm{~mL} * 3)$. The combined organic phase was then washed by brine $(20 \mathrm{~mL} * 2)$, dry with $\mathrm{Na}_{2} \mathrm{SO}_{4}$ and concentrated under rotavapor. The product $46(300 \mathrm{mg})$ was isolated through Prep-TLC. Yield is 62.6\%.

MS m/z (ESI): $\mathrm{C}_{19} \mathrm{H}_{19} \mathrm{ClFN}_{3} \mathrm{OS}[\mathrm{M}+\mathrm{H}]^{+}: 392.1$, found 392.3. 
vi: Compound 46 (100 mg, $0.26 \mathrm{mmol}$ ), 2-methoxyacetohydrazide (133 mg, $1.28 \mathrm{mmol}$ ) were dissolved in THF (5.0 mL) followed by addition of trifluoroacetic acid $(29 \mathrm{mg}, 0.26 \mathrm{mmol})$. The reaction mixture was stirred for $3 \mathrm{~h}$ at $70{ }^{\circ} \mathrm{C}$. The solution was the concentrated under reduced pressure. The product 12 (10 mg, yellow solid) was isolated through Prep-TLC. Yield is $9.0 \%$.

HRMS m/z (ESI): $\mathrm{C}_{21} \mathrm{H}_{21} \mathrm{ClFN}_{5} \mathrm{O}_{2}[\mathrm{M}+\mathrm{H}]^{+}:$430.1441, found 430.1442.

${ }^{1} \mathrm{H}$ NMR (400 MHz, $\left.\mathrm{CDCl}_{3}\right): \delta 8.16(\mathrm{~s}, 1 \mathrm{H}), 7.56$ (d, 1H, J=8.8 Hz), 7.27 (t, 1H, J=6.28 Hz), 7.09 (d, 1H, $J=8.8 \mathrm{~Hz}), 6.87-6.85(\mathrm{~m}, 2 \mathrm{H}), 4.27(\mathrm{~s}, 2 \mathrm{H}), 4.00$ (s, 3H), 3.66 (d, 1H, J=9.56 Hz), 3.45 (d, 2H, J=9.52 $\mathrm{Hz}), 3.36$ (d, 1H, J=8.96 Hz), 3.27 (s, 3H), 1.72-1.70 (m, 1H), 0.98-0.96 (m, 2H).

${ }^{13} \mathrm{C}$ NMR (100 MHz, $\left.\mathrm{CDCl}_{3}\right)$ : 164.23, 162.85-160.34, 157.31, 149.36, 145.51, 137.53, 136.60-136.50,

133.29-133.24, 132.93-132.84, 124.64, 117.12-116.92, 114.02-113.78, 111.64, 63.73, 57.78, 54.90,

$54.03,51.72,30.61,23.55,15.01$.

(1S,5R)-1-(2-chloro-4-fluorophenyl)-3-(5-(methoxymethyl)-4-(6-methoxypyridin-3-yl)-4H-1,2,4triazol-3-yl)-3-azabicyclo[3.1.0]hexane

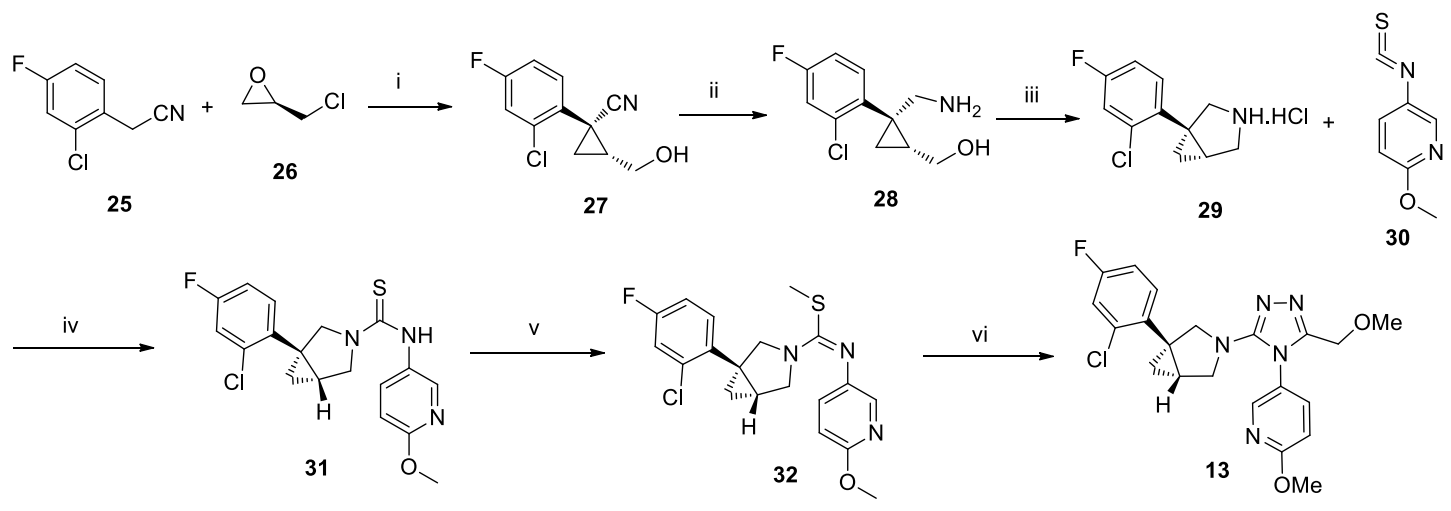

i: 3-chloro-4-fluorophenylacetonitrile $(1.0 \mathrm{~g}, 5.9 \mathrm{mmol})$ was dissolved in a cooled THF $(8.0 \mathrm{~mL})$ at - 20 ${ }^{\circ} \mathrm{C}$, followed by slow addition of NaHMDS $(2.2 \mathrm{~g}, 11.8 \mathrm{mmol})$. The reaction was stirred for $30 \mathrm{mins}$ and $R$-epichlorohydrin $(600 \mathrm{mg}, 6.49 \mathrm{mmol})$ was added. The reaction was allowed to slowly warm up to room temperature. After $2 \mathrm{~h}$, the reaction was stopped by $\mathrm{NH}_{4} \mathrm{Cl}(20 \mathrm{~mL}$, aqueous solution). The reaction was then separated and aqueous phase was extracted by ethyl acetate $(50 \mathrm{~mL} * 3)$. The combined organic phase was then concentrated under reduced pressure. The crude product $27(1.35 \mathrm{~g})$ was then applied to next step without further purification.

MS m/z (ESI): $\mathrm{C}_{11} \mathrm{H}_{9} \mathrm{ClFNO}[\mathrm{M}+\mathrm{H}]^{+}:$226.0, found 226.3.

ii: $\mathrm{LiAH}_{4}(672 \mathrm{mg}, 17.7 \mathrm{mmol})$ was dissolved in cooled THF $(15.0 \mathrm{~mL})$ at $0{ }^{\circ} \mathrm{C} .27(1.33 \mathrm{~g}, 5.9 \mathrm{mmol})$ was then slowly added. The reaction mixture warmed up to room temperature and was stirred for $15 \mathrm{~h}$. The solution was sequentially added water $(0.7 \mathrm{~mL}), \mathrm{NaOH}$ aqueous solution $(0.7 \mathrm{~mL}, 10 \%)$, water $(2.1$ $\mathrm{mL}$ ). The mixture was filtrated and filtration was concentrated to afford aminol 28 (1.4 g), which was directly applied into next step without further purification.

MS m/z (ESI): $\mathrm{C}_{11} \mathrm{H}_{13} \mathrm{ClFNO}[\mathrm{M}+\mathrm{H}]^{+}:$230.1, found 230.3.

iii: 28 (1.35 g, $5.9 \mathrm{mmol})$ was dissolved in cooled $\mathrm{CH}_{2} \mathrm{Cl}_{2}(8.0 \mathrm{~mL})$ at $0{ }^{\circ} \mathrm{C}$, thionyl chloride $(1.05 \mathrm{~g}, 8.85$ mmol) was slowly added. The reaction slowly warmed up and was stirred for $3 \mathrm{~h}$. The mixture was concentrated under reduced pressure to afford amine $29(1.3 \mathrm{~g})$, which was directly applied into next step without further purification.

$\mathrm{MS} \mathrm{m} / \mathrm{z}$ (ESI): $\mathrm{C}_{11} \mathrm{H}_{11} \mathrm{ClFN}[\mathrm{M}+\mathrm{H}]^{+}:$212.1, found 212.2. 
iv: crude product $29(1.06 \mathrm{~g}, 5.0 \mathrm{mmol})$ and 5-isothiocyanato-2-methoxypyridine $30(1.25 \mathrm{~g}, 7.5 \mathrm{mmol})^{1}$ were dissolved in THF $(20.0 \mathrm{~mL})$. The reaction mixture was stirred for $2 \mathrm{~h}$. The solution was then concentrated under reduced pressure. The crude product $31(1.9 \mathrm{~g})$ in the residue was utilized without further purification.

MS m/z (ESI): $\mathrm{C}_{18} \mathrm{H}_{17} \mathrm{ClFN}_{3} \mathrm{OS}[\mathrm{M}+\mathrm{H}]^{+}:$378.1, found 378.2 .

v: $31(1.86 \mathrm{~g}, 5.0 \mathrm{mmol})$ were dissolved in cooled THF $\left(30.0 \mathrm{~mL}, 0{ }^{\circ} \mathrm{C}\right)$ followed by addition of $\mathrm{KO}^{\mathrm{t}} \mathrm{Bu}$ (2.2 g, $20 \mathrm{mmol})$. The reaction mixture was stirred for $1 \mathrm{~h}$ before the addition of TsOMe (1.86 $\mathrm{g}, 10.0$ mmol). The reaction was allowed to slowly warm up and stirred for $15 \mathrm{~h}$. The reaction was stopped by ice water $(90 \mathrm{~mL})$ and separated. The aqueous phase was extracted by ethyl acetate $(50 \mathrm{~mL} * 3)$. The combined organic phase was then concentrated under rotavapor. The product $32(700 \mathrm{mg})$ was isolated through silica gel chromatagraphy. Yield is $33 \%$.

MS m/z (ESI): $\mathrm{C}_{19} \mathrm{H}_{19} \mathrm{ClFN}_{3} \mathrm{OS}[\mathrm{M}+\mathrm{H}]^{+}:$392.1, found 392.3 .

vi: 32 (180 mg, $0.46 \mathrm{mmol}$ ), 2-methoxyacetohydrazide (239 mg, $2.3 \mathrm{mmol}$ ) were dissolved in THF (8.0 $\mathrm{mL}$ ) followed by addition of trifluoroacetic acid $(52 \mathrm{mg}, 0.46 \mathrm{mmol})$. The reaction mixture was stirred for $3 \mathrm{~h}$ at $70{ }^{\circ} \mathrm{C}$. The solution was the concentrated under reduced pressure. The product 13 (150 mg, yellow solid) was isolated through high performance liquid chromatography. Yield is $75 \%$.

The e.e. of compound $\mathbf{1 3}$ was determined by waters e2695-2489. Chromatographic column was agilent SB C18, 4.6*150 mm (5 um). Column temerature was $35^{\circ} \mathrm{C}$. Speed was $1.0 \mathrm{~mL} / \mathrm{min}$. The gradient mobile phase was: $0 \mathrm{~min}$ : $95 \%\left(0.1 \%\right.$ TFA- $\left.\mathrm{H}_{2} \mathrm{O}\right)+5 \%(0.08 \%-\mathrm{ACN})$ to $30 \mathrm{~min}: 5 \%\left(0.1 \%\right.$ TFA- $\left.\mathrm{H}_{2} \mathrm{O}\right)+95 \%$ (0.08\%-ACN). The e.e. of compound 13 was $97 \%(254 \mathrm{nM})$ and $97 \%(214 \mathrm{nM})$.

HRMS m/z (ESI): $\mathrm{C}_{21} \mathrm{H}_{21} \mathrm{ClFN}_{5} \mathrm{O}_{2}[\mathrm{M}+\mathrm{H}]^{+}:$430.1441, found 430.1445.

LRMS m/z (ESI): $\mathrm{C}_{21} \mathrm{H}_{21} \mathrm{ClFN}_{5} \mathrm{O}_{2}[\mathrm{M}+\mathrm{H}]^{+}:$430.1, found 430.3.

${ }^{1} \mathrm{H}$ NMR (400 MHz, $\left.\mathrm{CDCl}_{3}\right): \delta 8.22(\mathrm{~d}, 1 \mathrm{H}, J=2.8 \mathrm{~Hz}), 7.66(\mathrm{~d}, 1 \mathrm{H}, J=8.8 \mathrm{~Hz}), 7.27(\mathrm{t}, 1 \mathrm{H}, J=6.28 \mathrm{~Hz})$, $7.10(\mathrm{~d}, 1 \mathrm{H}, J=8.8 \mathrm{~Hz}), 6.91-6.89(\mathrm{~m}, 2 \mathrm{H}), 4.24$ (s, 2H), 4.01 (s, 3H), 3.78 (d, 1H, J=9.56 Hz), 3.57$3.55(\mathrm{~m}, 2 \mathrm{H}), 3.53(\mathrm{~d}, 1 \mathrm{H}, J=9.28 \mathrm{~Hz}), 3.25(\mathrm{~s}, 3 \mathrm{H}), 1.81-1.79(\mathrm{~m}, 1 \mathrm{H}), 1.10(\mathrm{t}, 1 \mathrm{H}), 0.95(\mathrm{t}, 1 \mathrm{H})$ 。 ${ }^{13} \mathrm{C}$ NMR (100 MHz, $\left.\mathrm{CDCl}_{3}\right): 164.29,162.95,160.47,157.41,149.46,145.60,137.60,136.70,136.60$, 133.36, 133.05, 132.96, 124.73, 117.22, 116.98, 114.09, 113.88, 111.73, 63.83, 57.84, 54.99, 54.11, $51.81,30.71,23.66,15.14$.

\section{(1S,5R)-1-(2-chloro-4-fluorophenyl)-3-(5-(ethoxymethyl)-4-(6-methoxypyridin-3-yl)-4H-1,2,4-} triazol-3-yl)-3-azabicyclo[3.1.0]hexane
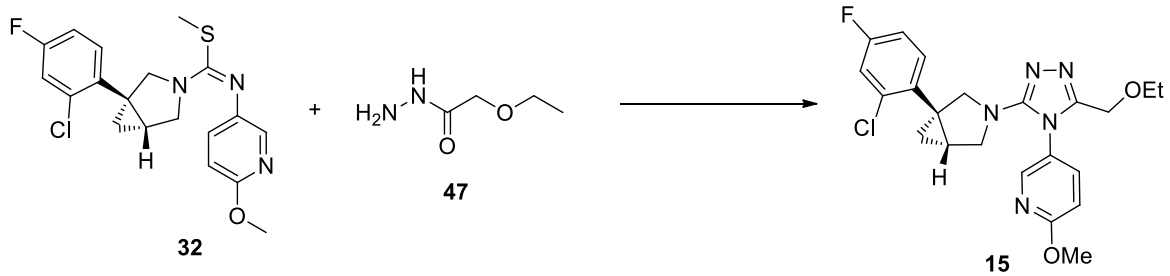

Compound 32 (40 mg, $0.1 \mathrm{mmol}$ ), 2-ethoxyacetohydrazide (60 mg, $0.51 \mathrm{mmol}$ ) were dissolved in THF $(5.0 \mathrm{~mL})$ followed by addition of trifluoroacetic acid $(12 \mathrm{mg}, 0.1 \mathrm{mmol})$. The reaction mixture was stirred for $3 \mathrm{~h}$ at $70{ }^{\circ} \mathrm{C}$. The solution was the concentrated under reduced pressure. The product 15 (10 $\mathrm{mg}$, light yellow solid) was isolated through prep-TLC. Yield is $20.3 \%$.

HRMS m/z (ESI): $\mathrm{C}_{22} \mathrm{H}_{23} \mathrm{ClFN}_{5} \mathrm{O}_{2}[\mathrm{M}+\mathrm{H}]^{+}:$444.1597, found 444.1592. 
${ }^{1} \mathrm{H}$ NMR (400 MHz, $\left.\mathrm{CDCl}_{3}\right): \delta 8.15(\mathrm{~s}, 1 \mathrm{H}), 7.56(\mathrm{~d}, 1 \mathrm{H}, J=8.8 \mathrm{~Hz}), 7.27(\mathrm{t}, 1 \mathrm{H}, J=6.28 \mathrm{~Hz}), 7.08(\mathrm{~d}$, $1 \mathrm{H}, J=8.56 \mathrm{~Hz}), 7.05-6.86(\mathrm{~m}, 2 \mathrm{H}), 4.31(\mathrm{~s}, 2 \mathrm{H}), 3.99(\mathrm{~s}, 3 \mathrm{H}), 3.62-3.60(\mathrm{~m}, 1 \mathrm{H}), 3.45-3.42(\mathrm{~m}, 4 \mathrm{H})$, $3.35(\mathrm{~d}, 1 \mathrm{H}, J=9.28 \mathrm{~Hz}), 1.72-1.70(\mathrm{~m}, 1 \mathrm{H}), 1.09(\mathrm{t}, 3 \mathrm{H}, J=7.04 \mathrm{~Hz}), 0.97-0.95(\mathrm{~m}, 2 \mathrm{H})$.

${ }^{13} \mathrm{C}$ NMR (100 MHz, $\left.\mathrm{CDCl}_{3}\right): 164.31,162.78-160.43,157.42,149.17,145.62,137.81,136.54-136.43$, 133.28-133.24, 132.97-132.89, 124.54, 117.18-116.93, 114.03-113.81, 111.72, 68.82, 62.46, 54.94, $54.07,51.76,30.68,23.63,15.21,15.15$.

(1S,5R)-1-(2-chloro-4-fluorophenyl)-3-(5-((2-fluoroethoxy)methyl)-4-(6-methoxypyridin-3-yl)-4H1,2,4-triazol-3-yl)-3-azabicyclo[3.1.0]hexane

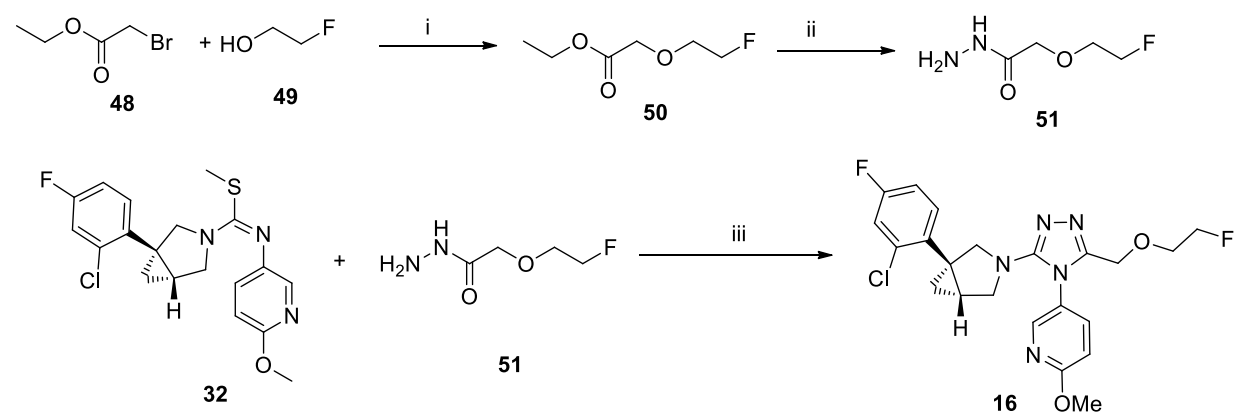

i: 2-fluoroethanol $49(800 \mathrm{mg}, 12.49 \mathrm{mmol})$ and $\mathrm{NaH}(1.74 \mathrm{~g}, 10.42 \mathrm{mmol})$ were added into THF (30 $\mathrm{mL})$, followed by the addition of 2-bromo ethyl acetate 48 (1.74 g, $10.42 \mathrm{mmol})$ after $2 \mathrm{~h}$. The reaction was stirred $15 \mathrm{~h}$ and was quenched by water $(30 \mathrm{~mL})$. The solution was separated and aqueous phase was extracted by ethyl acetate $\left(50 \mathrm{~mL}^{*} 3\right)$. The combined organic phase was washed by brine $(50 \mathrm{~mL} * 3)$ and concentrated under reduced pressure to deliver crude product ester $\mathbf{5 0}(300 \mathrm{mg})$, which was applied to next step without further purification.

$\mathrm{MS} \mathrm{m} / \mathrm{z}$ (ESI): $\mathrm{C}_{6} \mathrm{H}_{11} \mathrm{FO}_{3}[\mathrm{M}+\mathrm{H}]^{+}:$151.1, found 151.2.

ii: 50 (250 mg, $1.67 \mathrm{mmol})$ and hydrazine hydrate $(83 \%, 213 \mathrm{mg})$ were dissolved in ethanol in a sealed tube. The reaction was stirred for $15 \mathrm{~h}$ at $80{ }^{\circ} \mathrm{C}$. The solution was then concentrated to afford crude product 51 (250 mg), which was applied to next step without further purification.

MS m/z (ESI): $\mathrm{C}_{4} \mathrm{H}_{9} \mathrm{FN}_{2} \mathrm{O}_{2}[\mathrm{M}+\mathrm{H}]^{+}:$137.1, found 137.1.

iii: 32 (30 mg, $0.08 \mathrm{mmol})$, crude product $51(31 \mathrm{mg}, 0.23 \mathrm{mmol})$ were dissolved in THF $(5.0 \mathrm{~mL})$ followed by addition of trifluoroacetic acid $(9 \mathrm{mg}, 0.08 \mathrm{mmol})$. The reaction mixture was stirred for $1 \mathrm{~h}$ at $65{ }^{\circ} \mathrm{C}$. The solution was the concentrated under reduced pressure. The product 16 (10 mg, yellow oil) was isolated through prep-TLC. Yield is $26.4 \%$.

HRMS m/z (ESI): $\mathrm{C}_{22} \mathrm{H}_{22} \mathrm{ClF}_{2} \mathrm{~N}_{5} \mathrm{O}_{2}[\mathrm{M}+\mathrm{H}]^{+}:$462.1503, found 462.1495 .

${ }^{1} \mathrm{H}$ NMR (400 MHz, $\left.\mathrm{CDCl}_{3}\right): \delta \quad 8.17$ (s, 1H), 7.59 (d, 1H, J=8.8 Hz), 7.27 (t, 1H, J=6.28 Hz), 7.09 (d, $1 \mathrm{H}, J=8.6 \mathrm{~Hz}), 6.87-6.85(\mathrm{~m}, 2 \mathrm{H}), 4.53(\mathrm{t}, 1 \mathrm{H}, J=4.0 \mathrm{~Hz}), 4.41(\mathrm{~s}, 3 \mathrm{H}), 3.99(\mathrm{~s}, 3 \mathrm{H}), 3.64-3.62(\mathrm{~m}, 4 \mathrm{H})$, 3.42-3.40 (m, 2H), 1.73-1.71 (m, 1H), 0.98-0.95 (m,2H).

${ }^{13} \mathrm{C}$ NMR (100 MHz, $\left.\mathrm{CDCl}_{3}\right)$ : 164.33, 162.79-160.43, 157.41, 149.15, 145.62, 137.80, 136.54, 136.44, $133.29,133.25,132.99,132.90,124.54,117.19,116.94,114.04,113.83,111.72,83.34,81.66,68.91$, $68.72,62.46,54.93,54.08,51.76,30.65,23.60,15.13$.

(1S,5R)-1-(2-chloro-4-fluorophenyl)-3-(4-(6-methoxypyridin-3-yl)-5-(((tetrahydro-2H-pyran-4yl)oxy)methyl)-4H-1,2,4-triazol-3-yl)-3-azabicyclo[3.1.0]hexane 


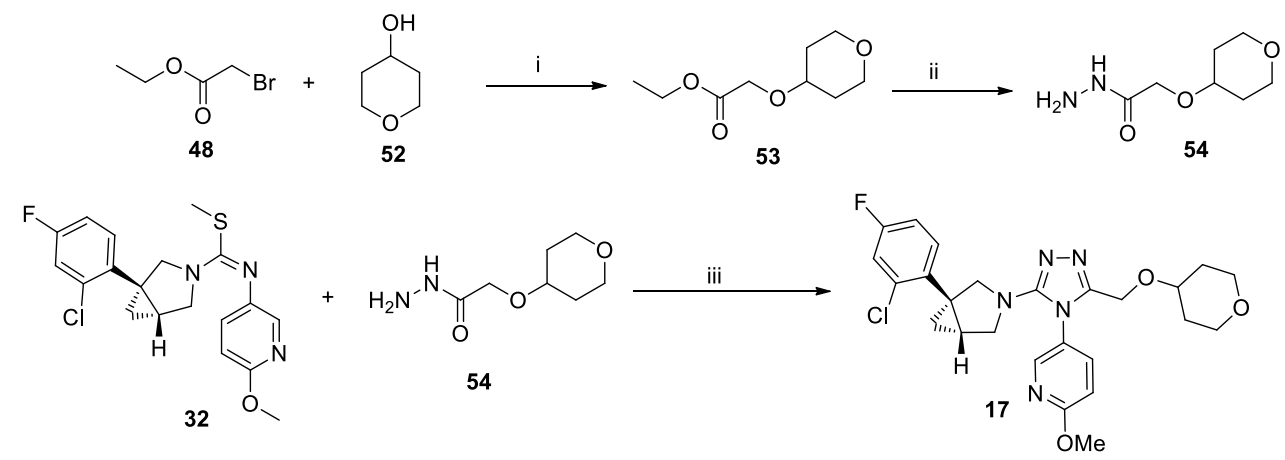

i: Tetrahydro-4-pyranol 52 (1.0 g, $9.8 \mathrm{mmol})$ and $\mathrm{NaH}(352 \mathrm{mg}, 14.7 \mathrm{mmol})$ were added in ice/watercooled THF (150 mL). After stirring $30 \mathrm{~min}$, 2-bromo ethyl acetate 48 (1.96 g, $11.8 \mathrm{mmol}$ ) was added. After removing the ice/water bath, the mixture was stirred $6 \mathrm{~h}$ before the addition of ice cold water (30 $\mathrm{mL}$ ). The reaction mixture was then separated and aqueous phase was then extracted by ethyl acetate (30 $\mathrm{mL} * 3)$. The combined organic phase was washed by brine $(50 \mathrm{~mL} * 3)$ and dried over $\mathrm{Na}_{2} \mathrm{SO}_{4}$ and concentrated under rotavapor, which delivered product ester $\mathbf{5 3}(1.8 \mathrm{~g})$. The yield is $87.9 \%$.

MS m/z (ESI): $\mathrm{C}_{9} \mathrm{H}_{16} \mathrm{O}_{4}[\mathrm{M}+\mathrm{H}]^{+}:$189.1, found 189.2.

ii: Compound 53 (1.8 g, $9.6 \mathrm{mmol})$ and hydrazine hydrate $(83 \%, 478 \mathrm{mg}, 9.6 \mathrm{mmol})$ were dissolved in ethanol in a sealed tube. The reaction was stirred for $48 \mathrm{~h}$ at $80{ }^{\circ} \mathrm{C}$. The solution was then concentrated to afford crude product 54 (1.6 g), which was applied to next step without further purification.

MS m/z (ESI): $\mathrm{C}_{7} \mathrm{H}_{14} \mathrm{~N}_{2} \mathrm{O}_{3}[\mathrm{M}+\mathrm{H}]^{+}:$175.1, found 175.0.

iii: Compound 32 (40 mg, $0.1 \mathrm{mmol})$, crude product 54 (53 mg, $0.31 \mathrm{mmol})$ were dissolved in THF (10.0 $\mathrm{mL})$ followed by addition of trifluoroacetic acid $(1 \mathrm{mg}, 0.01 \mathrm{mmol})$. The reaction mixture was stirred for $3 \mathrm{~h}$ at $70^{\circ} \mathrm{C}$. The solution was the concentrated under reduced pressure. The product 17 (10 mg, yellow solid) was isolated through prep-TLC. Yield is $18.2 \%$.

HRMS m/z (ESI): $\mathrm{C}_{25} \mathrm{H}_{27} \mathrm{ClFN}_{5} \mathrm{O}_{3}[\mathrm{M}+\mathrm{H}]^{+}:$500.1859, found 500.1852 .

${ }^{1} \mathrm{H}$ NMR (400 MHz, $\left.\mathrm{CDCl}_{3}\right): \delta 8.19(\mathrm{~d}, 1 \mathrm{H}, J=2.7 \mathrm{~Hz}$ ), 7.57 (dd, 1H, J=2.5,2.5 Hz), 7.29-7.25 (m, 1H), $7.10(\mathrm{dd}, 1 \mathrm{H}, J=2.7,2.7 \mathrm{~Hz}), 6.88-6.86(\mathrm{~m}, 2 \mathrm{H}), 4.38$ (s, 2H), 4.01 (s, 3H), 3.83-3.75 (m, 2H), 3.69-3.61 (m, 1H), 3.54-3.45 (m, 1H), 3.44-3.30 (m, 5H), 1.82-1.73 (m, 2H), 1.48-1.43 (m, 2H), 0.99-0.97 (m,3H). (1S,5R)-1-(2-chloro-4-fluorophenyl)-3-(4-(6-methoxypyridin-3-yl)-5-((((S)-tetrahydrofuran-3yl)oxy)methyl)-4H-1,2,4-triazol-3-yl)-3-azabicyclo[3.1.0]hexane

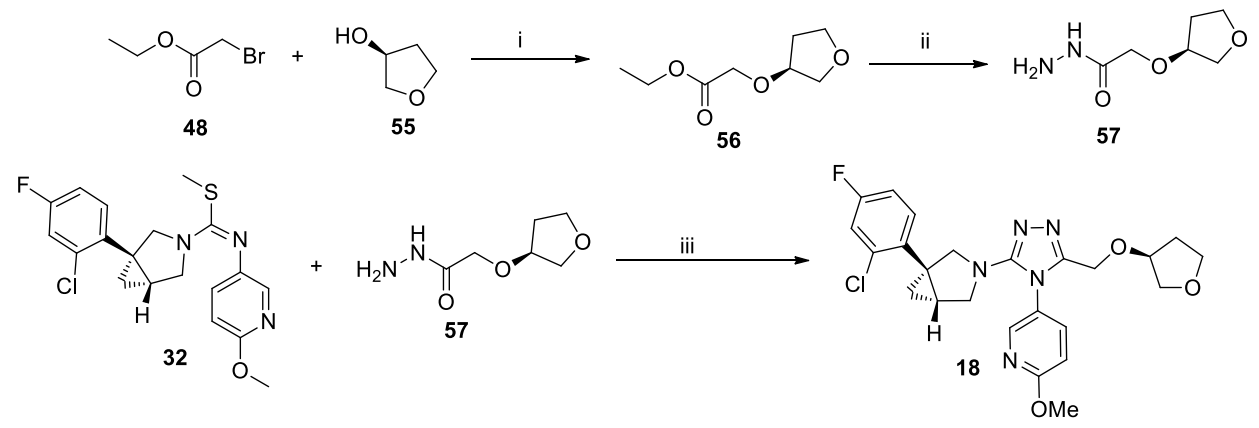

i: $(S)$-(+)-3-Hydroxytetrahydrofuran 55 (4.0 g, $45.4 \mathrm{mmol})$ and $\mathrm{NaH}(2.72 \mathrm{~g}, 68.1 \mathrm{mmol})$ were added in ice/water-cooled THF (150 mL). After stirring $30 \mathrm{~min}, 2$-bromo ethyl acetate 48 (7.58 g, $45.4 \mathrm{mmol})$ was added. After removal of the ice/water bath, the mixture was stirred $6 \mathrm{~h}$ before the addition of ice cold water $(30 \mathrm{~mL})$. The reaction mixture was then separated and aqueous phase was then extracted by 
ethyl acetate $(30 \mathrm{~mL} * 3)$. The combined organic phase was washed by brine $(50 \mathrm{~mL} * 3)$ and dried over $\mathrm{Na}_{2} \mathrm{SO}_{4}$ and concentrated under rotavapor, which delivered product $\mathbf{5 6}(4.5 \mathrm{~g})$.

MS m/z (ESI): $\mathrm{C}_{8} \mathrm{H}_{14} \mathrm{O}_{4}[\mathrm{M}+\mathrm{H}]^{+}:$175.1, found 175.2.

ii: product $56(1.0 \mathrm{~g}, 5.7 \mathrm{mmol})$ and hydrazine hydrate $(83 \%, 287 \mathrm{mg}, 5.7 \mathrm{mmol})$ were dissolved in ethanol in a sealed tube. The reaction was stirred for $18 \mathrm{~h}$ at $80{ }^{\circ} \mathrm{C}$. The solution was then concentrated to afford crude product $57(1.1 \mathrm{~g})$, which was applied to next step without further purification.

MS m/z (ESI): $\mathrm{C}_{6} \mathrm{H}_{12} \mathrm{~N}_{2} \mathrm{O}_{3}[\mathrm{M}+\mathrm{H}]^{+}:$161.1, found 161.2.

iii: Compound 32 (50 mg, $0.13 \mathrm{mmol})$, crude product $57(31 \mathrm{mg}, 0.19 \mathrm{mmol})$ were dissolved in THF $(20.0 \mathrm{~mL})$ followed by addition of trifluoroacetic acid $(1 \mathrm{mg}, 0.01 \mathrm{mmol})$. The reaction mixture was stirred for $3 \mathrm{~h}$ at $70{ }^{\circ} \mathrm{C}$. The solution was the concentrated under reduced pressure. The product 18 (15 $\mathrm{mg}$, white solid) was isolated through high performance liquid chromatography. Yield is $24.2 \%$.

HRMS m/z (ESI): $\mathrm{C}_{24} \mathrm{H}_{25} \mathrm{ClFN}_{5} \mathrm{O}_{3}[\mathrm{M}+\mathrm{H}]^{+}:$486.1703, found 486.1695.

${ }^{1} \mathrm{H}$ NMR (400 MHz, DMSO-d 6 ): $\delta 8.20(\mathrm{~s}, 1 \mathrm{H}), 7.60$ (d, 1H, J=8 Hz), 7.31-7.29 (m, 1H), $7.14(\mathrm{~d}, 1 \mathrm{H}$, $J=8 \mathrm{~Hz}), 6.91-6.89$ (m, 2H), 4.37 (s, 2H), 4.18-4.17 (m, 1H), 4.05 (s, 3H), 3.81-3.67 (m, 5H), 3.50 (d, $2 \mathrm{H}, J=12 \mathrm{~Hz}), 3.41$ (d, 1H, J=12 Hz), 1.77-1.63 (m, 3H), 1.02-1.00 (m, 2H).

${ }^{13} \mathrm{C}$ NMR (100 MHz, MeOH-d4): 164.3, 163.0, 160.5, 157.4, 149.4, 145.7, 137.7, 136.7, 133.0, 124.7, 117.2, 114.1, 111.7, 79.0, 72.6, 66.9, 60.7, 55.0, 54.1, 51.8, 32.3, 30.7, 23.7, 15.2 .

(1S,5R)-1-(2-chloro-4-fluorophenyl)-3-(4-(6-methoxypyridin-3-yl)-5-((((R)-tetrahydrofuran-3yl)oxy)methyl)-4H-1,2,4-triazol-3-yl)-3-azabicyclo[3.1.0]hexane

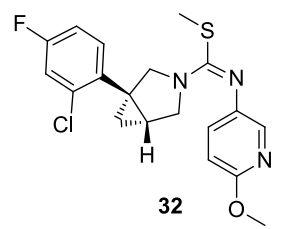<smiles>NNC(=O)CO[C@H]1CCOC1</smiles>

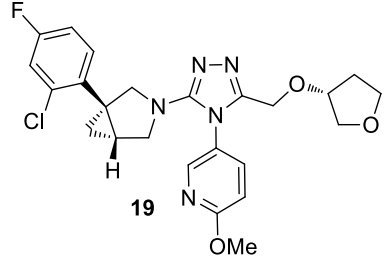

The synthesis of Compound 58 (white solid) is similar to 18, while the starting $(S)-(+)-3-$

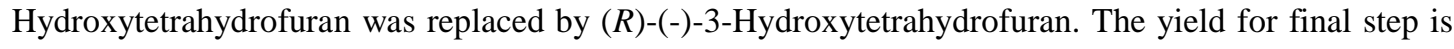
$13.2 \%$.

HRMS m/z (ESI): $\mathrm{C}_{24} \mathrm{H}_{25} \mathrm{ClFN}_{5} \mathrm{O}_{3}[\mathrm{M}+\mathrm{H}]^{+}:$486.1703, found 486.1700.

${ }^{1} \mathrm{H}$ NMR (400 MHz, CD 3 OD) $\delta 8.20(\mathrm{~s}, 1 \mathrm{H}), 7.59$ (d, 1H, J=8 Hz), 7.32-7.28 (m, 1H), 7.14 (dd, 1H, $J=8$, $2.8 \mathrm{~Hz}), 6.99-6.98(\mathrm{~m}, 1 \mathrm{H}), 6.92(\mathrm{~d}, 1 \mathrm{H}, J=8 \mathrm{~Hz}), 4.40-4.33(\mathrm{~m}, 2 \mathrm{H})$ 4.17-4.15 (m, 1H), $4.03(\mathrm{~s}, 3 \mathrm{H})$, 3.81-3.79 (m, 2H), 3.68-3.65 (m, 3H), 3.50 (d, 2H, J=12 Hz), 3.40 (d, 1H, J=12 Hz), 1.98-1.90 (m, 1H), 1.89-1.81 (m, 1H), 1.79-1.74 (m, 1H), 1.02-0.92 (m, 2H).

${ }^{13} \mathrm{C}$ NMR (100 MHz, MeOH-d4): 164.3, 163.0, 160.5, 157.4, 149.5, 145.7, 137.7, 136.7, 133.0, 124.7, 117.2, 114.1, 111.7, 79.0, 72.6, 66.9, 60.7, 55.0, 54.1, 51.8, 32.3, 30.7, 23.7, 15.2.

(1S,5R)-1-(2-chloro-4-fluorophenyl)-3-(5-(difluoromethyl)-4-(6-methoxypyridin-3-yl)-4H-1,2,4triazol-3-yl)-3-azabicyclo[3.1.0]hexane
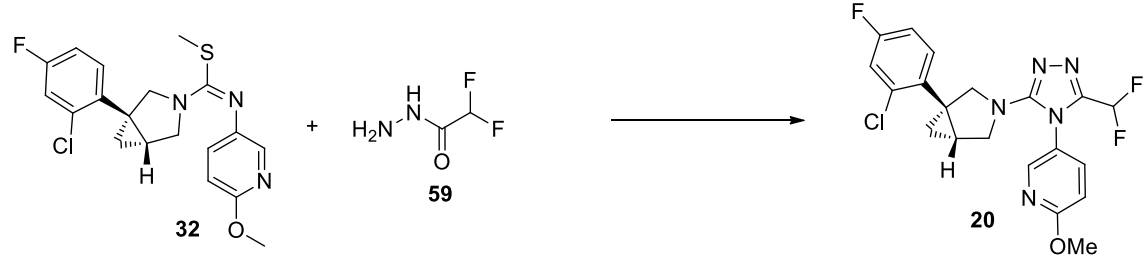
The synthesis of $\mathbf{2 0}$ (white solid) followed the simiar procedure of 18, while the compound $\mathbf{5 5}$ was replaced by 2,2-difluoroacetohydrazide 59. The yield was $10.8 \%$.

HRMS m/z (ESI): $\mathrm{C}_{20} \mathrm{H}_{17} \mathrm{ClF}_{3} \mathrm{~N}_{5} \mathrm{O}[\mathrm{M}+\mathrm{H}]^{+}:$436.1146, found 436.1150.

${ }^{1} \mathrm{H} \mathrm{NMR}\left(400 \mathrm{MHz}, \mathrm{CDCl}_{3}\right) \delta 8.21(\mathrm{~d}, 1 \mathrm{H}, J=2.2 \mathrm{~Hz}), 7.57(\mathrm{dd}, 1 \mathrm{H}, J=2.5,2.5 \mathrm{~Hz}), 7.35(\mathrm{~m}, 1 \mathrm{H}), 7.18$ (dd, 1H, J=2.5, 2.5 Hz), 6.99-6.79 (m, 2H), 6.78-6.52 (m, 1H), 4.02 (s, 3H), 3.70-3.62 (m, 1H), 3.49$3.42(\mathrm{~m}, 2 \mathrm{H}), 3.41(\mathrm{~d}, 1 \mathrm{H}, J=9 \mathrm{~Hz}), 1.89-1.82(\mathrm{~m}, 1 \mathrm{H}), 1.07-1.01(\mathrm{~m}, 1 \mathrm{H}), 0.98$ (t, 1H, J=4.8 Hz).

2-(5-((1S,5R)-1-(2-chloro-4-fluorophenyl)-3-azabicyclo[3.1.0]hexan-3-yl)-4-(6-methoxypyridin-3yl)-4H-1,2,4-triazol-3-yl)acetonitrile
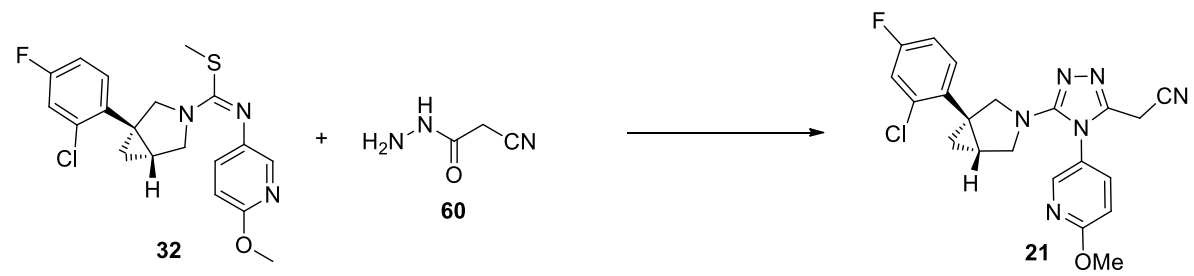

The synthesis of this compound followed the simiar procedure of $\mathbf{1 8}$, while the compound $\mathbf{5 7}$ was replaced by 2-cyanoacetohydrazide $\mathbf{6 0}$. The yield was $24.3 \%$.

HRMS m/z (ESI): $\mathrm{C}_{21} \mathrm{H}_{18} \mathrm{ClFN}_{6} \mathrm{O}[\mathrm{M}+\mathrm{H}]^{+}:$425.1287, found 425.1285.

${ }^{1} \mathrm{H}$ NMR (400 MHz, CD 30 D) $\delta 8.21(\mathrm{~d}, 1 \mathrm{H}, J=4 \mathrm{~Hz}), 7.63(\mathrm{dd}, 1 \mathrm{H}, J=8,2.8 \mathrm{~Hz}), 7.33-7.30(\mathrm{~m}, 1 \mathrm{H})$, 7.15 (dd, 1H, J=8, $2.8 \mathrm{~Hz}), 7.00$ (d, 1H, J=8 Hz), 6.98-6.97 (m, 1H), 4.06 (s, 3H), 3.72-3.69 (m, 3H), 3.49 (d, 2H, J=12 Hz), 3.42 (d, 1H, J=12 Hz), 1.80-1.76 (m, 1H), 1.06-0.98 (m, 2H).

${ }^{13} \mathrm{C}$ NMR (100 MHz, MeOH-d4): 165.0, 163.0, 160.5, 157.6, 146.0, 142.2, 137.8, 136.7, 133.2, 132.9, $123.7,117.3,114.2,112.7,55.0,54.3,51.9,30.8,23.7,15.8,15.3$.

(1S,5R)-1-(2-chloro-4-fluorophenyl)-3-(5-cyclopropyl-4-(6-methoxypyridin-3-yl)-4H-1,2,4-triazol3-yl)-3-azabicyclo[3.1.0]hexane
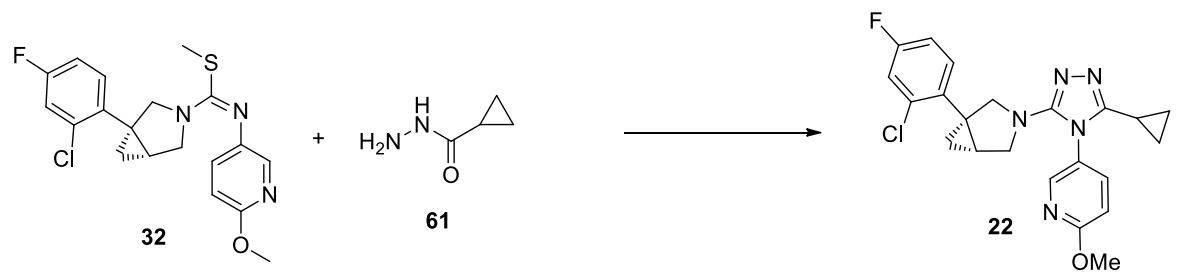

The synthesis of $\mathbf{2 2}$ (white solid) followed the simiar procedure of 18, while the compound $\mathbf{5 7}$ was replaced by cyclopropanecarbohydrazide $\mathbf{6 1}$. The yield was $27.5 \%$.

HRMS m/z (ESI): $\mathrm{C}_{22} \mathrm{H}_{21} \mathrm{ClFN}_{5} \mathrm{O}[\mathrm{M}+\mathrm{H}]^{+}:$426.1491, found 426.1493.

${ }^{1} \mathrm{H}$ NMR (400 MHz, CD $\left.30 D\right) \delta 8.24(\mathrm{~d}, 1 \mathrm{H}, J=4 \mathrm{~Hz}), 7.67(\mathrm{dd}, 1 \mathrm{H}, J=8,2.8 \mathrm{~Hz}), 7.30-7.25(\mathrm{~m}, 1 \mathrm{H})$, 7.17 (dd, 1H, J=8, $2.8 \mathrm{~Hz}), 6.94$ (d, 1H, J=8), 6.90-6.89 (m, 1H), 4.06 (s, 3H), 3.75 (dd, 1H, J=12, 6 Hz), 3.55-3.47 (m, 2H), 3.45 (d, 1H, J=12 Hz), 1.79-1.72 (m, 1H), 1.43-1.36 (m, 1H), 1.15-1.10 (m, 2H), 1.06-0.96 (m, 2H), 0.89-0.86 (m, 2H).

${ }^{13} \mathrm{C}$ NMR (100 MHz, MeOH-d4): 164.2, 162.9, 160.4, 156.6, 154.3, 145.7, 137.6, 136.7, 133.5, 133.1, $125.1,117.2,114.1,112.0,55.0,54.1,51.8,30.7,23.6,14.7,6.94,6.06$.

(1S,5R)-1-(2-chloro-3-fluorophenyl)-3-(5-(methoxymethyl)-4-(6-methoxypyridin-3-yl)-4H-1,2,4triazol-3-yl)-3-azabicyclo[3.1.0]hexane 


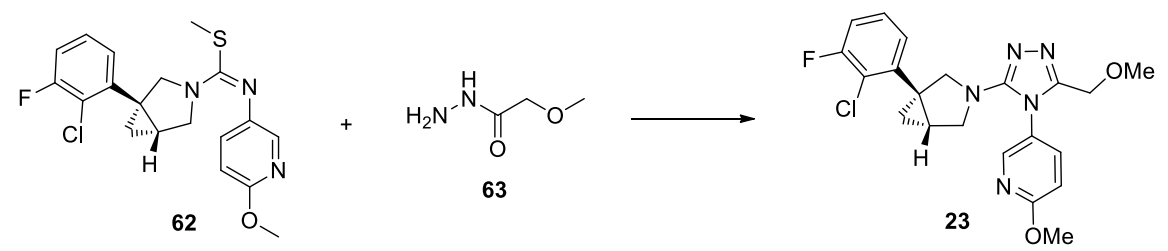

The synthesis of $\mathbf{2 3}$ (light yellow solid) followed the simiar procedure of $\mathbf{1 3}$, while the compound $\mathbf{2 5}$ was replaced by 2-(2-chloro-3-fluorophenyl)acetonitrile. The yield was $6.5 \%$.

HRMS m/z (ESI): $\mathrm{C}_{21} \mathrm{H}_{21} \mathrm{ClFN}_{5} \mathrm{O}_{2}[\mathrm{M}+\mathrm{H}]^{+}:$430.1441, found 430.1440.

${ }^{1} \mathrm{H}$ NMR (400 MHz, $\left.\mathrm{CDCl}_{3}\right): \delta 8.16(\mathrm{~s}, 1 \mathrm{H}), 7.56(\mathrm{~d}, 1 \mathrm{H}, J=8.8 \mathrm{~Hz}), 7.27(\mathrm{t}, 1 \mathrm{H}, J=6.28 \mathrm{~Hz}), 7.14(\mathrm{~d}, 2 \mathrm{H}$, $J=8.8 \mathrm{~Hz}), 6.85$ (d, 1H, $J=8.28 \mathrm{~Hz}), 4.27$ (s, 2H), 3.99 (s, 3H), 3.65 (d, 1H, J=9.8 Hz), 3.47 (d, 2H, $J=9.32$ $\mathrm{Hz}), 3.36$ (d, 1H, J=9.28 Hz), 3.27 (s, 3H), 1.77-1.75 (m, 1H), 1.01-0.99 (m, 2H).

${ }^{13} \mathrm{C}$ NMR (100 MHz, $\mathrm{CDCl}_{3}$ ): 164.21, 162.84-160.36, 157.32, 149.36, 145.49, 137.56, 134.54-134.44, 133.29-133.25, 124.54, 123.41-123.37, 117.13-116.88, 114.01-113.80, 111.63, 63.75, 57.76, 54.92, $54.01,51.73,30.62,23.57,15.06$.

\section{(1S,5R)-3-(4-(benzo[d][1,3] dioxol-5-yl)-5-(methoxymethyl)-4H-1,2,4-triazol-3-yl)-1-(2-chloro-4- fluorophenyl)-3-azabicyclo[3.1.0]hexane}

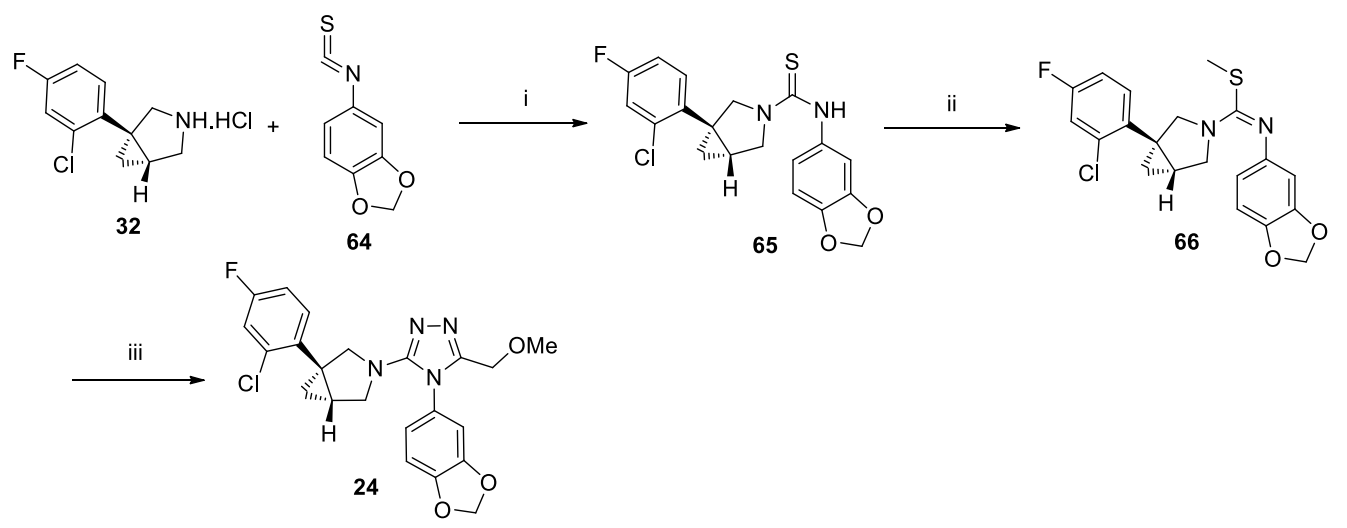

i: Compound $32(245 \mathrm{mg}, 1.16 \mathrm{mmol})$ and 5-isothiocyanatobenzo[d][1,3]dioxole $64(311 \mathrm{mg}, 1.74$ $\mathrm{mmol})^{3}$ were dissolved in THF $(10.0 \mathrm{~mL})$. The reaction mixture was stirred for $2 \mathrm{~h}$. The solution was then concentrated under reduced pressure. The crude product $65(450 \mathrm{mg})$ in the residue was utilized without further purification.

MS m/z (ESI): $\mathrm{C}_{19} \mathrm{H}_{16} \mathrm{ClFN}_{2} \mathrm{O}_{2} \mathrm{~S}[\mathrm{M}+\mathrm{H}]^{+}:$391.1, found 391.2.

ii: 65 (391 mg, $1.0 \mathrm{mmol})$ were dissolved in cooled THF $\left(30.0 \mathrm{~mL}, 0^{\circ} \mathrm{C}\right)$ followed by addition of $\mathrm{KO}^{\mathrm{t}} \mathrm{Bu}$ (337 mg, $3 \mathrm{mmol}$ ). The reaction mixture was stirred for $2 \mathrm{~h}$ before the addition of TsOMe (372 $\mathrm{mg}, 2.0$ mmol). The reaction was allowed to slowly warm up and stirred for $15 \mathrm{~h}$. The reaction was stopped by ice water $(80 \mathrm{~mL})$ and separated. The aqueous phase was extracted by ethyl acetate $(50 \mathrm{~mL} * 3)$. The combined organic phase was washed by brine $\left(50 \mathrm{~mL}^{* 3}\right)$ and then concentrated under rotavapor. The product 66 (150 mg) was isolated through prep-TLC. Yield is $33.3 \%$.

MS m/z (ESI): $\mathrm{C}_{20} \mathrm{H}_{18} \mathrm{ClFN}_{2} \mathrm{O}_{2} \mathrm{~S}[\mathrm{M}+\mathrm{H}]^{+}:$405.1, found 405.3.

iii: Compound 66 ( $80 \mathrm{mg}, 0.2 \mathrm{mmol}$ ), 2-methoxyacetohydrazide (103 mg, $0.99 \mathrm{mmol}$ ) were dissolved in THF (5.0 mL) followed by addition of trifluoroacetic acid $(23 \mathrm{mg}, 0.2 \mathrm{mmol})$. The reaction mixture was stirred for $3 \mathrm{~h}$ at $70{ }^{\circ} \mathrm{C}$. The solution was the concentrated under reduced pressure. The product 24 (20 $\mathrm{mg}$, yellow oil) was isolated through high performance liquid chromatography. Yield is $21.7 \%$. 
HRMS m/z (ESI): $\mathrm{C}_{22} \mathrm{H}_{20} \mathrm{ClFN}_{4} \mathrm{O}_{3}[\mathrm{M}+\mathrm{H}]^{+}:$443.1281, found 443.1281.

${ }^{1} \mathrm{H}$ NMR (400 MHz, CDCl 3 ): $\delta 7.27(\mathrm{t}, 1 \mathrm{H}, J=6.28 \mathrm{~Hz}), 7.09(\mathrm{~d}, 1 \mathrm{H}, J=8.8 \mathrm{~Hz}), 6.88-6.85(\mathrm{~m}, 2 \mathrm{H}), 6.83$ $6.81(\mathrm{~m}, 2 \mathrm{H}), 6.10$ (s, 2H), 4.28 (s, 2H), 3.65 (d, 1H, J=9.8 Hz), 3.47 (d, 2H, J=9.3 Hz), 3.34 (d, 1H, $J=9.3 \mathrm{~Hz}), 3.32(\mathrm{~s}, 3 \mathrm{H}), 1.72-1.69(\mathrm{~m}, 1 \mathrm{H}), 1.01-0.99(\mathrm{~m}, 2 \mathrm{H})$ 。

${ }^{13} \mathrm{C}$ NMR (100 MHz, $\left.\mathrm{CDCl}_{3}\right): 162.87-160.39,157.33,149.36,148.93,148.91,145.49,137.53,136.62-$ 136.52, 133.29-133.24, 132.97-132.89, 124.64, 117.15-116.94, 114.02-113.79, 111.65, 101.23, 63.75, $57.76,54.90,51.71,30.64,23.58,15.11$.

5'-fluoro-1-(5-(methoxymethyl)-4-(6-methoxypyridin-3-yl)-4H-1,2,4-triazol-3-yl)-3'Hspiro[azetidine-3,1'-isobenzofuran]

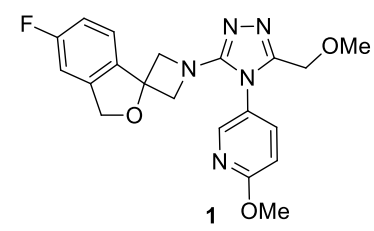

HRMS m/z (ESI): $\mathrm{C}_{20} \mathrm{H}_{20} \mathrm{FN}_{5} \mathrm{O}_{3}[\mathrm{M}+\mathrm{H}]^{+}:$398.1623, found 398.1653.

${ }^{1} \mathrm{H}$ NMR (400 MHz, $\left.\mathrm{CDCl}_{3}\right): \delta 8.23(\mathrm{~s}, 1 \mathrm{H}), 7.64(\mathrm{~d}, 1 \mathrm{H}, J=8.8 \mathrm{~Hz}), 7.45(\mathrm{~m}, 1 \mathrm{H}), 7.05(\mathrm{~m}, 1 \mathrm{H}), 6.86-$ $6.83(\mathrm{~m}, 2 \mathrm{H}), 5.03(\mathrm{~s}, 2 \mathrm{H}), 4.36(\mathrm{~s}, 2 \mathrm{H}), 4.22$ (d, 2H, J=8.8 Hz), 4.00 (s, 2H), 3.97 (s, 3H), 3.32 (s, 3H). ${ }^{13} \mathrm{C}$ NMR (100 MHz, $\mathrm{CDCl}_{3}$ ): 164.27, 161.23-158.75, 157-42, 153.17-153.13, 149.17, 145.52, 141.25$141.15,137.52$, 128.64-128.55, 124.65, 114.73-114.52, 111.67, 108.51-108.30, 85.62, 68.53, 68.47, $63.76,61.23,57.78,54.91$.

6'-fluoro-1-(5-(methoxymethyl)-4-(6-methoxypyridin-3-yl)-4H-1,2,4-triazol-3-yl)spiro[azetidine3,2'-chroman]

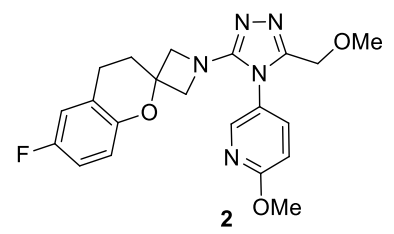

HRMS m/z (ESI): $\mathrm{C}_{21} \mathrm{H}_{22} \mathrm{FN}_{5} \mathrm{O}_{3}[\mathrm{M}+\mathrm{H}]^{+}:$412.1779, found 412.1773.

${ }^{1} \mathrm{H}$ NMR (400 MHz, CD $\left.3 \mathrm{OD}\right): \quad \delta 8.28(\mathrm{~d}, \mathrm{~J}=2.6 \mathrm{~Hz}, 1 \mathrm{H}), 7.80(\mathrm{dd}, 1 \mathrm{H}, J=2.8,8.8 \mathrm{~Hz}), 6.97(\mathrm{~d}, 1 \mathrm{H}$, $J=8.8 \mathrm{~Hz}), 6.86-6.74(\mathrm{~m}, 3 \mathrm{H}), 4.33(\mathrm{~s}, 2 \mathrm{H}), 4.00(\mathrm{~s}, 3 \mathrm{H}), 3.92-3.86(\mathrm{~m}, 2 \mathrm{H}), 3.85$ - $3.80(\mathrm{~m}, 2 \mathrm{H})$, $3.26(\mathrm{~s}, 3 \mathrm{H}), 2.79(\mathrm{t}, 2 \mathrm{H}, J=6.6 \mathrm{~Hz}), 2.11(\mathrm{t}, 2 \mathrm{H}, J=6.6 \mathrm{~Hz})$.

${ }^{13} \mathrm{C}$ NMR (100 MHz, MeOH-d4): $\quad \delta 164.5,158.8,156.1,149.7,148.8,145.6,137.5,123.8,122.3,118.3$, $115.5,115.2,114.8,114.6,112.0,74.3,64.0,58.2,54.3,28.7,21.9$.

5-(2-chloro-4-fluorophenoxy)-2-(5-(methoxymethyl)-4-(6-methoxypyridin-3-yl)-4H-1,2,4-triazol3-yl)octahydrocyclopenta[c]pyrrole

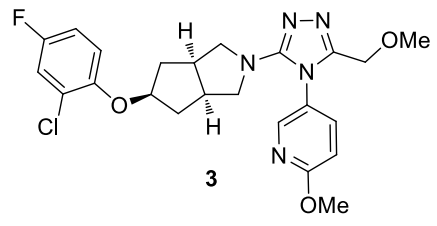

HRMS m/z (ESI): $\mathrm{C}_{23} \mathrm{H}_{25} \mathrm{ClFN}_{5} \mathrm{O}_{3}[\mathrm{M}+\mathrm{H}]^{+}:$474.1703, found 474.1713.

${ }^{1} \mathrm{H}$ NMR (400 MHz, CD $\left.3 \mathrm{OD}\right): \delta 8.29(\mathrm{~d}, 1 \mathrm{H}, J=2.6 \mathrm{~Hz}), 7.81(\mathrm{dd}, 1 \mathrm{H}, J=2.8,8.8 \mathrm{~Hz}), 7.19(\mathrm{dd}, 1 \mathrm{H}, J$ = 2.8, 8.2 Hz), 7.09 - $6.94(\mathrm{~m}, 3 \mathrm{H}), 4.32(\mathrm{~s}, 2 \mathrm{H}), 4.01(\mathrm{~s}, 3 \mathrm{H}), 3.32-3.31(\mathrm{~m}, 1 \mathrm{H}), 3.26(\mathrm{~s}, 3 \mathrm{H}), 3.20$ 
(dd, 2H, $J=7.0,9.6 \mathrm{~Hz}), 2.98$ (d, 2H, $J=9.6 \mathrm{~Hz}), 2.96-2.87$ (m, $2 \mathrm{H}), 2.15$ (dd, $2 \mathrm{H}, J=5.8,13.6 \mathrm{~Hz}$ ), $1.66-1.55(\mathrm{~m}, 2 \mathrm{H})$.

${ }^{13} \mathrm{C}$ NMR (100 MHz, MeOH-d4): $\delta$ 164.5, 158.8, 158.5, 156.1, 149.7, 148.8, 145.6, 137.5, 123.8, 122.3, $118.3,115.5,115.2,114.8,114.6,112.0,74.3,64.0,63.9,58.2,54.3,40.7,39.1$.

3-(2-chloro-4-fluorophenoxy)-8-(5-(methoxymethyl)-4-(6-methoxypyridin-3-yl)-4H-1,2,4-triazol3-yl)-8-azabicyclo[3.2.1]octane

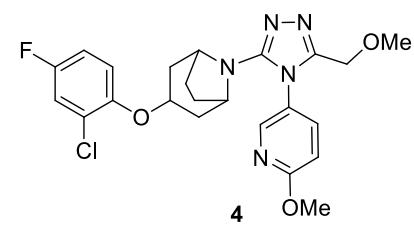

HRMS m/z (ESI): $\mathrm{C}_{23} \mathrm{H}_{25} \mathrm{ClFN}_{5} \mathrm{O}_{3}[\mathrm{M}+\mathrm{H}]^{+}: 474.1703$, found 474.1713 .

${ }^{1} \mathrm{H}$ NMR (400 MHz, CD $\left.3 \mathrm{OD}\right): \delta 8.33(\mathrm{~d}, 1 \mathrm{H}, J=2.5 \mathrm{~Hz}), 7.85(\mathrm{dd}, 1 \mathrm{H}, J=8.8,2.8 \mathrm{~Hz}), 7.18(\mathrm{dd}, 1 \mathrm{H}, J=$ 8.0, $3.0 \mathrm{~Hz}), 7.13(\mathrm{dd}, 1 \mathrm{H}, J=9.0,5.0 \mathrm{~Hz}), 6.95-7.04(\mathrm{~m}, 2 \mathrm{H}), 4.60-4.71(\mathrm{~m}, 1 \mathrm{H}), 4.35(\mathrm{~s}, 2 \mathrm{H}), 4.02(\mathrm{~s}, 3 \mathrm{H})$, 3.94(br, 2H), 3.27(s, 3H), 1.95-2.06(m, 4H), 1.77-1.88(m, 4H).

3-(2-chloro-4-fluorophenyl)-6-(5-(methoxymethyl)-4-(6-methoxypyridin-3-yl)-4H-1,2,4-triazol-3yl)-3,6-diazabicyclo[3.2.0]heptane

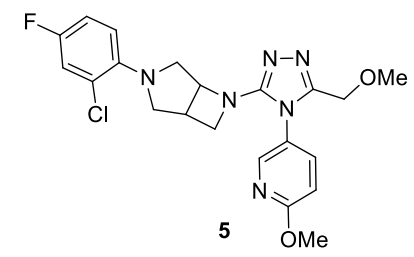

HRMS m/z (ESI): $\mathrm{C}_{21} \mathrm{H}_{22} \mathrm{ClFN}_{6} \mathrm{O}_{2}[\mathrm{M}+\mathrm{H}]^{+}: 445.1550$, found 445.1451 .

${ }^{1} \mathrm{H}$ NMR $\left(400 \mathrm{MHz}, \mathrm{CD}_{3} \mathrm{OD}\right): \delta 8.30(\mathrm{~d}, 1 \mathrm{H}, J=4 \mathrm{~Hz}), 7.82(\mathrm{dd}, 1 \mathrm{H}, J=8,2.8 \mathrm{~Hz}), 7.21(\mathrm{dd}, 1 \mathrm{H}, J=8,2.8$ $\mathrm{Hz}), 7.08-7.07(\mathrm{~m}, 1 \mathrm{H}), 7.02-7.01(\mathrm{~m}, 1 \mathrm{H}), 6.99(\mathrm{~d}, 1 \mathrm{H}, J=8 \mathrm{~Hz}), 4.60-4.57(\mathrm{~m}, 1 \mathrm{H}), 4.36(\mathrm{dd}, 2 \mathrm{H}, J=20$, $12 \mathrm{~Hz}), 3.99(\mathrm{~s}, 3 \mathrm{H}), 3.83-3.82(\mathrm{~m}, 1 \mathrm{H}), 3.74(\mathrm{~d}, 1 \mathrm{H}, \mathrm{J}=12 \mathrm{~Hz}), 3.47(\mathrm{~s}, 1 \mathrm{H}), 3.42-3.40(\mathrm{~m}, 2 \mathrm{H}), 3.37(\mathrm{~s}, 3 \mathrm{H})$, 2.84-2.80(m, 1H), 2.42-2.39(m, 1H).

${ }^{13} \mathrm{C}$ NMR (400 MHz, MeOH-d4): $\delta$ 164.9, 155.5, 154.5, 149.7, 146.3, 139.8, 132.3, 124.7, 118.9, 117.6, $114.7,108.3,105.6,74.9,63.7,59.1,57.9,55.9,55.0,54.3,35.1$.

6-(2-chloro-4-fluorophenyl)-3-(5-(methoxymethyl)-4-(6-methoxypyridin-3-yl)-4H-1,2,4-triazol-3yl)-3,6-diazabicyclo[3.2.0]heptane

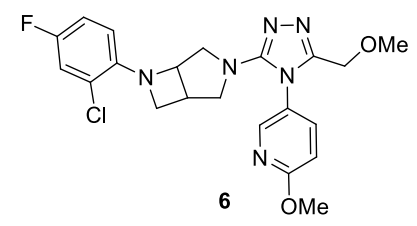

HRMS m/z (ESI): $\mathrm{C}_{21} \mathrm{H}_{22} \mathrm{ClFN}_{6} \mathrm{O}_{2}[\mathrm{M}+\mathrm{H}]^{+}: 445.1550$, found 445.1461 .

${ }^{1} \mathrm{H}$ NMR $\left(400 \mathrm{MHz}, \mathrm{CD}_{3} \mathrm{OD}\right): \delta 8.30(\mathrm{~d}, 1 \mathrm{H}, J=2.8 \mathrm{~Hz}), 7.82(\mathrm{dd}, 1 \mathrm{H}, J=2.7,2.7 \mathrm{~Hz}), 7.21(\mathrm{dd}, 1 \mathrm{H}, \mathrm{J}=$ 2.8, $2.9 \mathrm{~Hz}), 7.13-7.07(\mathrm{~m}, 1 \mathrm{H}), 7.04-6.95(\mathrm{~m}, 2 \mathrm{H}), 4.36-4.26(\mathrm{~m}, 2 \mathrm{H}), 4.09-4.06(\mathrm{~m}, 1 \mathrm{H}), 3.99(\mathrm{~s}, 3 \mathrm{H})$, $3.83-3.78(\mathrm{~m}, 1 \mathrm{H}), 3.74(\mathrm{~d}, 1 \mathrm{H}, J=11.1 \mathrm{~Hz}), 3.47(\mathrm{~s}, 1 \mathrm{H}), 3.43-3.41(\mathrm{~m}, 2 \mathrm{H}), 3.28(\mathrm{~s}, 3 \mathrm{H}), 2.85-2.81(\mathrm{~m}, 1 \mathrm{H})$, $2.43(\mathrm{dd}, 1 \mathrm{H}, J=3.8,3.8 \mathrm{~Hz})$. 
5-(3-(1-(2-chloro-4-fluorobenzyl)piperidin-4-yl)-5-(methoxymethyl)-4H-1,2,4-triazol-4-yl)-2methoxypyridine

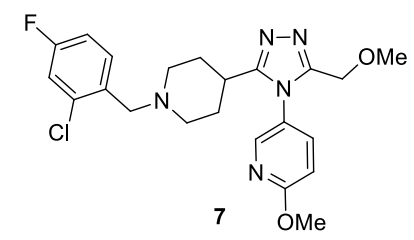

HRMS m/z (ESI): $\mathrm{C}_{22} \mathrm{H}_{25} \mathrm{ClFN}_{5} \mathrm{O}_{2}[\mathrm{M}+\mathrm{H}]^{+}:$:446.1754, found 446.1753 .

${ }^{1} \mathrm{H}$ NMR $\left(400 \mathrm{MHz}, \mathrm{CD}_{3} \mathrm{OD}\right) \delta 8.28(\mathrm{~d}, 1 \mathrm{H}, J=2.3 \mathrm{~Hz}), 7.80(\mathrm{dd}, 1 \mathrm{H}, J=8.8,2.8 \mathrm{~Hz}), 7.70(\mathrm{t}, 1 \mathrm{H}, J=7.0$, $6.8 \mathrm{~Hz}), 7.47(\mathrm{dd}, 1 \mathrm{H}, J=8.5,2.5 \mathrm{~Hz}), 7.29(\mathrm{td}, 1 \mathrm{H}, J=8.3,2.8 \mathrm{~Hz}), 7.03(\mathrm{~d}, 1 \mathrm{H}, \mathrm{J}=8.8 \mathrm{~Hz}), 4.48(\mathrm{~s}, 2 \mathrm{H})$, 4.41(s, 2H), 4.03(s, 3H), 3.57-3.68(m, 2H), 3.27(s, 3H), 3.19(br, 2H), 3.00(br, 1H), 2.17(s, 4H).

1-(2-chloro-4-fluorobenzyl)-4-(5-(methoxymethyl)-4-(6-methoxypyridin-3-yl)-4H-1,2,4-triazol-3yl)piperazine

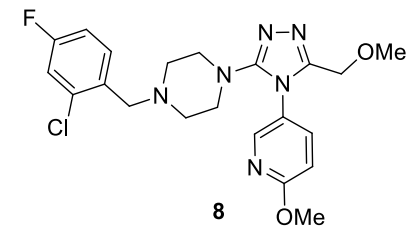

HRMS m/z (ESI): $\mathrm{C}_{21} \mathrm{H}_{24} \mathrm{ClFN}_{6} \mathrm{O}_{2}[\mathrm{M}+\mathrm{H}]^{+}: 447.1706$, found 447.1713.

${ }^{1} \mathrm{H}$ NMR $\left(400 \mathrm{MHz}, \mathrm{CDCl}_{3}\right): \delta 8.24(\mathrm{~d}, 1 \mathrm{H}, J=2.7 \mathrm{~Hz}), 7.65(\mathrm{dd}, 1 \mathrm{H}, J=2.8,2.5 \mathrm{~Hz}), 7.39-7.38(\mathrm{~m}, 1 \mathrm{H})$, 7.07(dd,1H, $J=2.5,2.5 \mathrm{~Hz}), 6.93-6.92(\mathrm{~m}, 1 \mathrm{H}), 6.87(\mathrm{~d}, 1 \mathrm{H}, J=8.8 \mathrm{~Hz}), 4.3(\mathrm{~s}, 2 \mathrm{H}), 3.98(\mathrm{~s}, 3 \mathrm{H}), 3.53(\mathrm{~s}, 2 \mathrm{H})$, $3.3(\mathrm{~s}, 3 \mathrm{H}), 3.11-3.08(\mathrm{~m}, 4 \mathrm{H}), 2.45-2.27(\mathrm{~m}, 4 \mathrm{H})$.

${ }^{13} \mathrm{C}$ NMR $\left(100 \mathrm{MHz}, \mathrm{CDCl}_{3}\right): 164.3,162.9,160.5,158.9,150.3,144.8,136.8,134.9,131.9,124.9,117.0$, $114.3,112.1,64.1,58.6,58.2,54.3,52.4,52.4,49.1,49.1$.

5-(3-(4-(2-chloro-4-fluorophenyl)piperidin-1-yl)-5-(methoxymethyl)-4H-1,2,4-triazol-4-yl)-2methoxypyridine

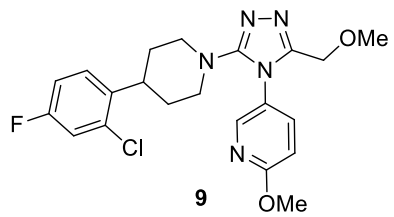

HRMS m/z (ESI): $\mathrm{C}_{21} \mathrm{H}_{23} \mathrm{ClFN}_{5} \mathrm{O}_{2}[\mathrm{M}+\mathrm{H}]^{+}: 432.1597$, found 432.1593 .

${ }^{1} \mathrm{H}$ NMR $\left(400 \mathrm{MHz}, \mathrm{CD}_{3} \mathrm{OD}\right) \delta 8.34(\mathrm{~d}, 1 \mathrm{H}, J=2.4 \mathrm{~Hz}), 7.87(\mathrm{dd}, 1 \mathrm{H}, J=2.4,8.8 \mathrm{~Hz}), 7.34(\mathrm{dd}, 1 \mathrm{H}, J=$ 6.0, $8.8 \mathrm{~Hz}$ ), 7.20 (dd, 1H, J= 2.4, 8.8 Hz), 7.10 - 6.99 (m, 2 H), 4.37 (s, $2 \mathrm{H}), 4.01$ (s, $3 \mathrm{H}), 3.49$ (m, 2 H), 3.29 (s, 3 H), $3.21-3.09$ (m, 1 H), 3.06 - 2.95 (m, 2 H), 1.83 - 1.74 (m, 2 H), 1.72 - 1.58 (m, 2 H). 5-(3-(3-(2-chloro-4-fluorophenyl)pyrrolidin-1-yl)-5-(methoxymethyl)-4H-1,2,4-triazol-4-yl)-2methoxypyridine

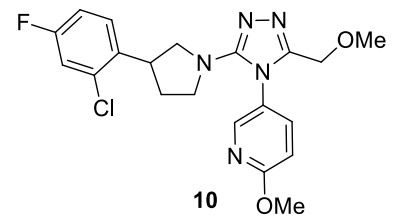

HRMS m/z (ESI): $\mathrm{C}_{20} \mathrm{H}_{21} \mathrm{ClFN}_{5} \mathrm{O}_{2}[\mathrm{M}+\mathrm{H}]^{+}:$418.1441, found 418.1439.

${ }^{1} \mathrm{H}$ NMR $\left(400 \mathrm{MHz}, \mathrm{CD}_{3} \mathrm{OD}\right) \delta 8.29(\mathrm{~d}, 1 \mathrm{H}, J=2.4 \mathrm{~Hz}), 7.81(\mathrm{dd}, 1 \mathrm{H}, J=2.4,8.8 \mathrm{~Hz}), 7.36(\mathrm{dd}, 1 \mathrm{H}, J=$ 6.0, $8.8 \mathrm{~Hz}), 7.22(\mathrm{dd}, 1 \mathrm{H}, J=2.4,8.8 \mathrm{~Hz}), 7.08(\mathrm{dt}, 1 \mathrm{H}, J=2.4,8.4 \mathrm{~Hz}), 6.95(\mathrm{~d}, 1 \mathrm{H}, J=8.8 \mathrm{~Hz}), 4.36$ - 
4.25 (m, 2 H), 3.99 (s, $3 \mathrm{H}), 3.81$ (q, 1H, J= 7.2 Hz), 3.66 (dd, 1H, J= 7.4, $9.4 \mathrm{~Hz}), 3.28$ (m, 2H), 3.25 (s,

$3 \mathrm{H}), 3.19$ (dd, $1 \mathrm{H}, J=7.2,9.4 \mathrm{~Hz}), 2.34-2.23(\mathrm{~m}, 1 \mathrm{H}), 2.00-2.06(\mathrm{~m}, 1 \mathrm{H})$.

\section{Spectrum of SHR1653}

${ }^{1}$ H-NMR 


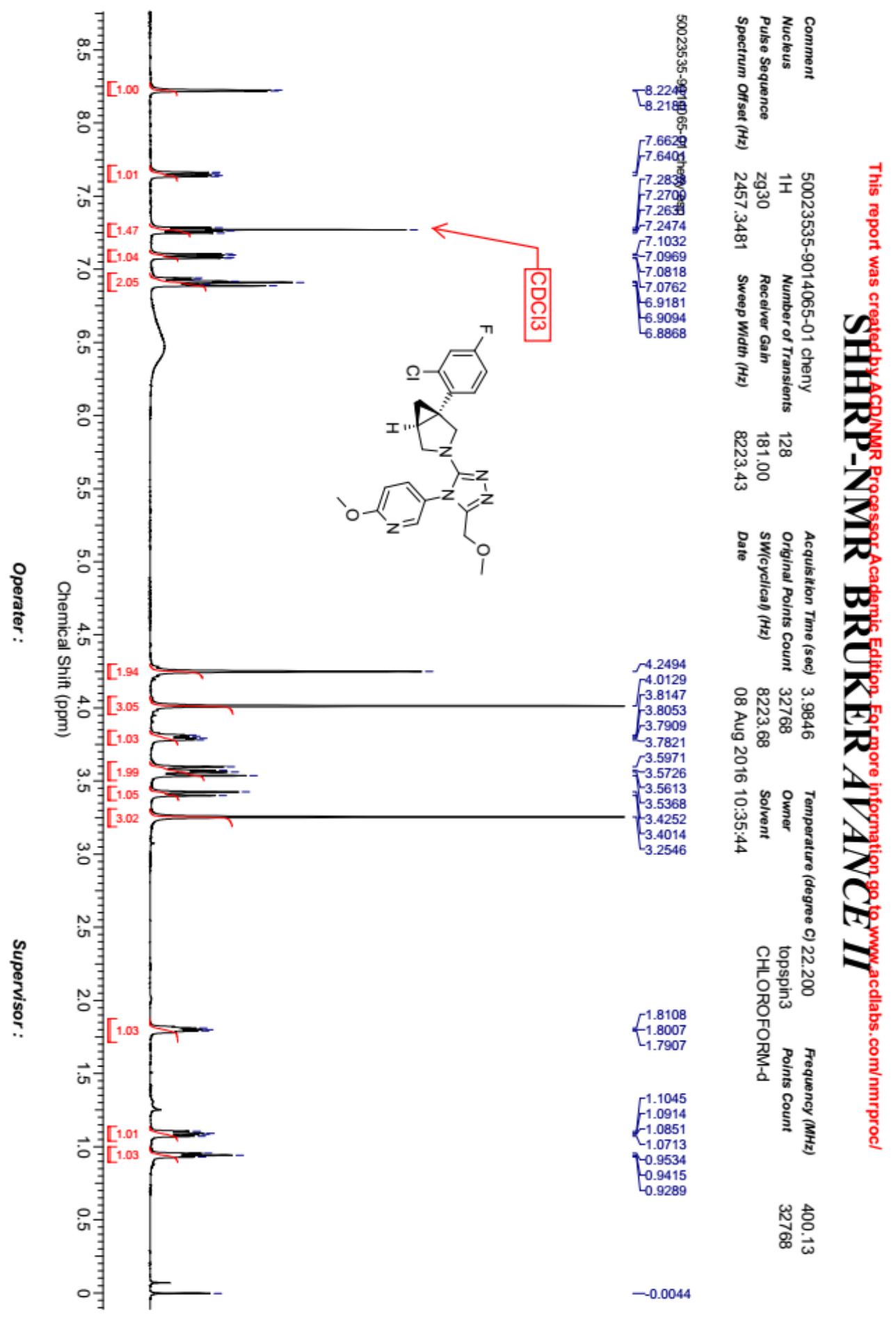

${ }^{13}$ C-NMR 


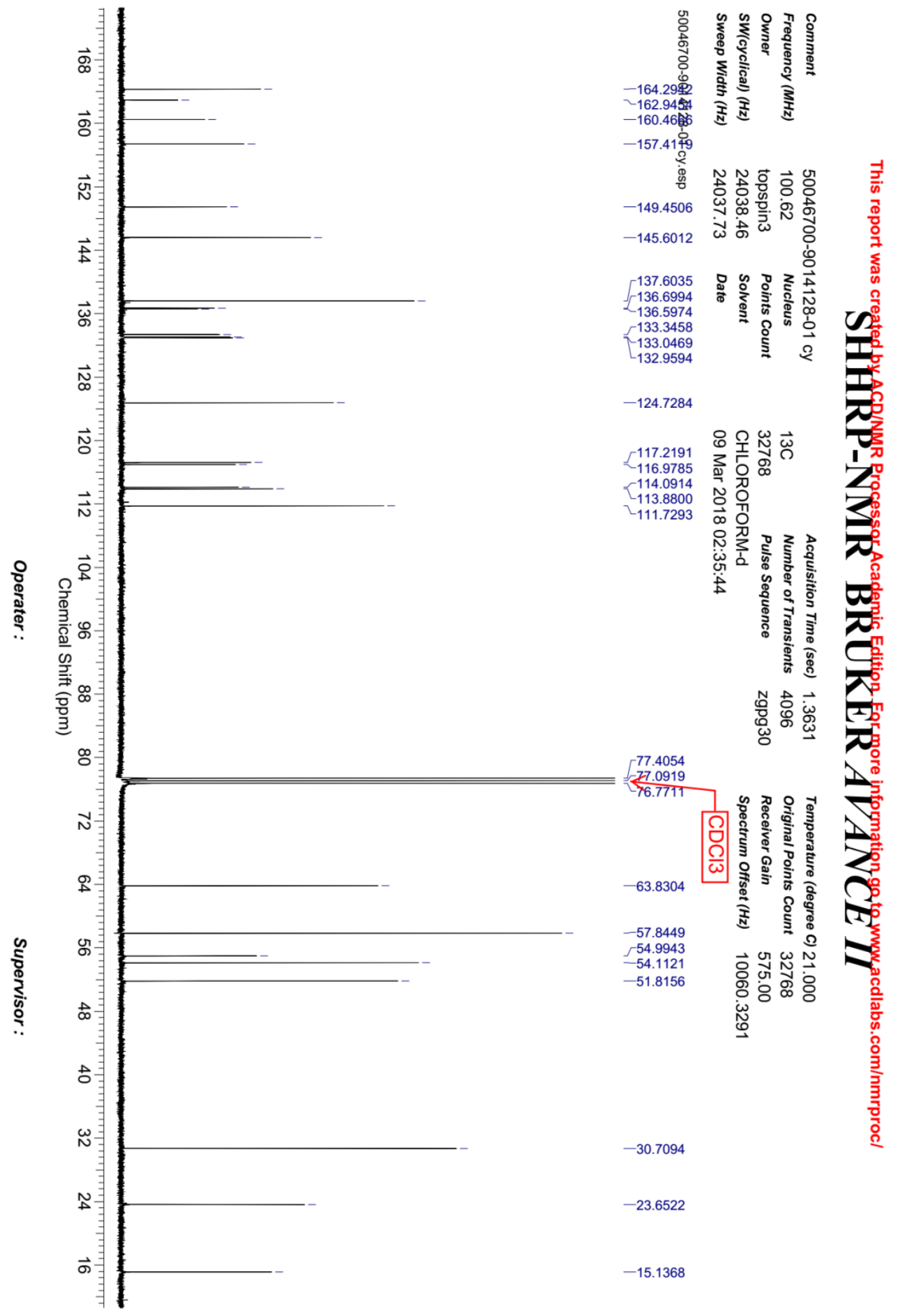

Chiral HPLC analysis -1(214 nM) 


\begin{tabular}{|c|c|c|c|}
\hline \multicolumn{2}{|r|}{ SAMPLE } & \multicolumn{2}{|c|}{ INFORMATION } \\
\hline Sample Name: & $70010295-9118226-01$ & Acquired By: & System \\
\hline Sample Type: & Unknown & Sample Set Name: & 201707271 \\
\hline Vial: & 7 & Acq. Method Set: & M 595 30MIN AD \\
\hline Injection \#: & 1 & Processing Method & HPLC3 \\
\hline Injection Volume: & $3.00 \mathrm{ul}$ & Channel Name: & W2489 ChA \\
\hline Run Time: & 30.0 Minutes & Proc. Chnl. Descr.: & W2489 ChA $214 \mathrm{~nm}$ \\
\hline Date Acquired: & 7/27/2017 11:37:46 AM CST & & \\
\hline Date Processed: & 7/27/2017 1:14:22 PM CST & & \\
\hline
\end{tabular}

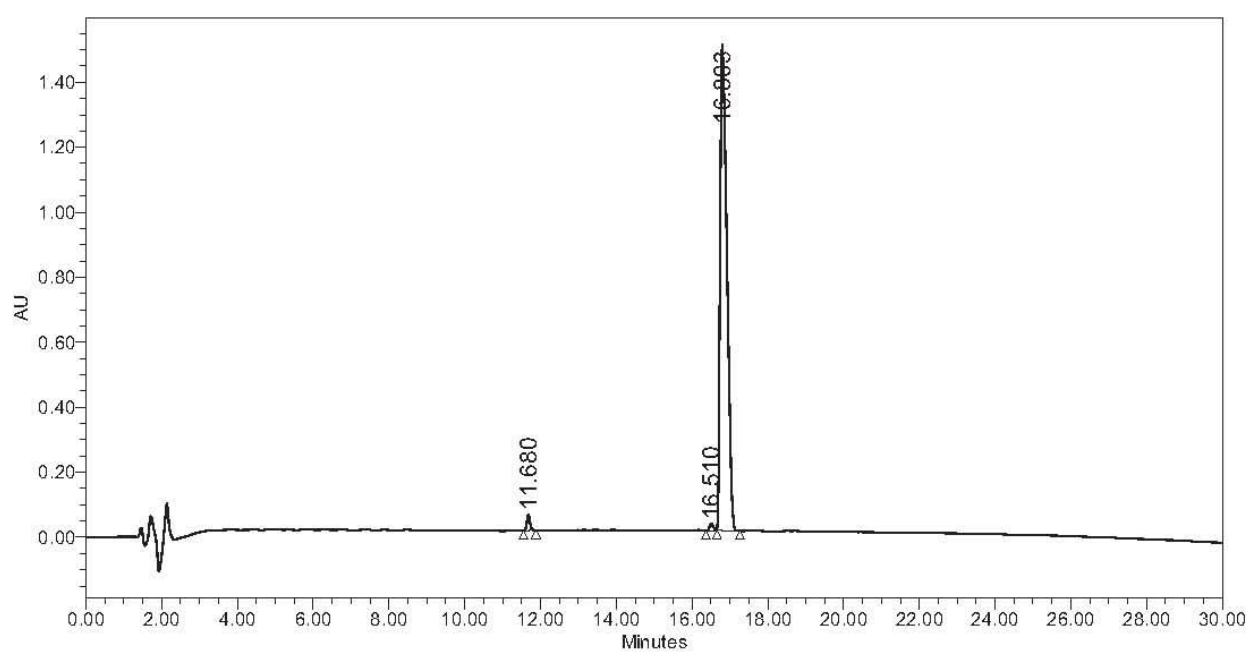

\begin{tabular}{|r|c|r|r|r|r|}
\hline & RT & Area & $\%$ Area & Height & USP Resolution \\
\hline 1 & 11.680 & 290323 & 1.53 & 49365 & \\
\hline 2 & 16.510 & 139241 & 0.73 & 21273 & 28.89 \\
\hline 3 & 16.803 & 18544260 & 97.74 & 1496080 & 1.11 \\
\hline
\end{tabular}

Reported by User: System

Report Method: HPLC

Report Method ID 6121

Page: 1 of 1
Project Name: Defaults Date Printed:

$7 / 27 / 2017$

1:16:28 PM PRC

Chiral HPLC analysis -2 (254 nM) 


\section{Empowert2}

HPLC

\begin{tabular}{|llll|}
\hline & \multicolumn{2}{c|}{ S A M P L E } & I N F O R M A T I O N \\
\hline \hline Sample Name: & $70010295-9118226-01$ & Acquired By: & System \\
Sample Type: & Unknown & Sample Set Name: & 20170727 1 \\
Vial: & 7 & Acq. Method Set: & M 5 95 30MIN AD \\
Injection \#: & 1 & Processing Method & HPLC3 \\
Injection Volume: & 3.00 ul & Channel Name: & W2489 ChB \\
Run Time: & 30.0 Minutes & Proc. Chnl. Descr.: & W2489 ChB 254nm \\
& & \\
Date Acquired: & $7 / 27 / 2017$ 11:37:46 AM CST & & \\
Date Processed: & $7 / 27 / 2017$ 1:15:56 PM CST & & \\
\hline
\end{tabular}

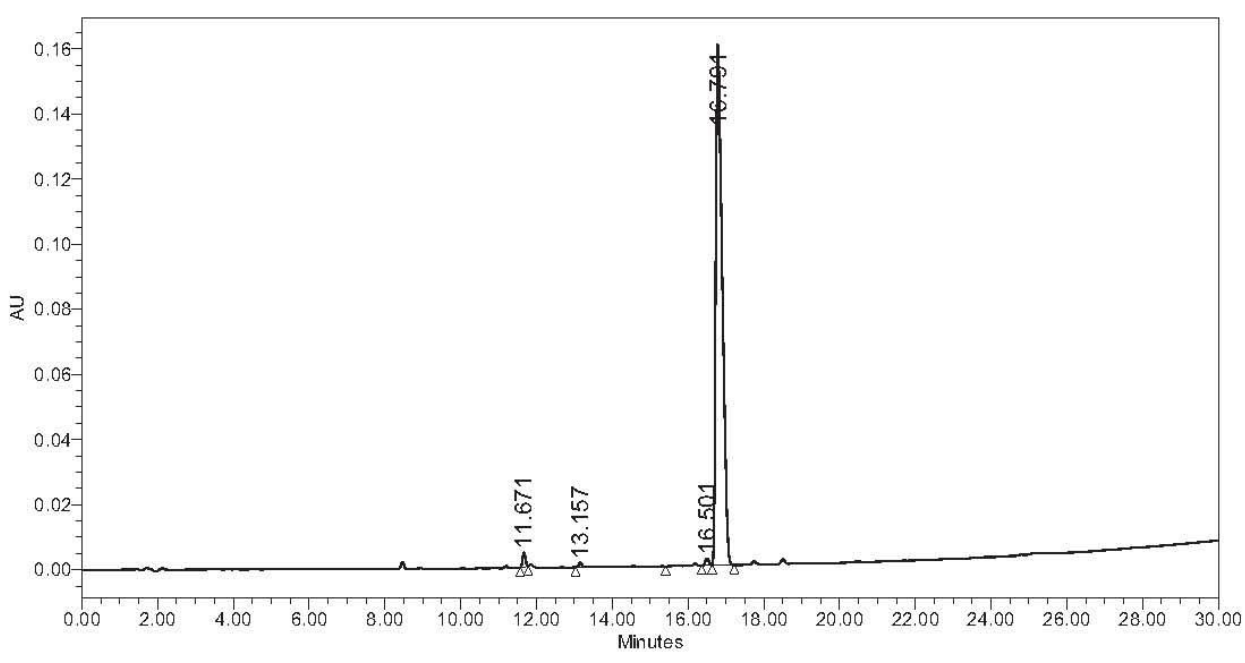

\begin{tabular}{|l|c|c|r|r|r|}
\hline & RT & Area & $\%$ Area & Height & USP Resolution \\
\hline 1 & 11.671 & 24793 & 1.28 & 4522 & \\
\hline 2 & 13.157 & 16155 & 0.83 & 1404 & 9.37 \\
\hline 3 & 16.501 & 14296 & 0.74 & 2204 & 19.29 \\
\hline 4 & 16.791 & 1885522 & 97.15 & 160919 & 1.11 \\
\hline
\end{tabular}

Reported by User: System

Report Method: HPLC

Report Method ID 6121

Page: 1 of 1
Project Name: Defaults Date Printed:

7/27/2017

1:17:21 PM PRC 


\section{Methods for in vitro, in vivo, and pharmacokinectic assays}

\section{Chemicals and reagents}

Recombinant human P450 isoenzymes (CYP1A2, CYP1B1, CYP2A6, CYP2B6, CYP2C8, CYP2C9, CYP2C19, CYP2D6, CYP3A4, CYP3A5, and CYP4A11) were purchased from BD Gentest (Woburn, MA). Purified water was generated by Milli-Q gradient water purification system (Millipore, Molsheim, France). Other commercially available reagents were of analytical grade.

\section{LC-MS/MS instrumentation and general conditions}

LC-MS/MS for in vitro and in vivo sample bioanalysis consisted of an HPLC system (Shimadzu, Japan) equipped with a binary solvent manager, an auto sampler and an AB4000 triple quadrupole mass spectrometer (AB SCIEX) with electrospray ionization (ESI) source. Data acquisition and analysis were performed using Analyst software (AB SCIEX). A Hypersil Gold C8 column (30 mm × 2.1 mm i.d., 1.9 $\mu \mathrm{m}$; Thermo, USA) thermostatted at $35^{\circ} \mathrm{C}$. The flow rate was set to $0.3 \mathrm{~mL} / \mathrm{min}$. The mobile phase consisted of water with $0.2 \%$ formic acid (A) and acetonitrile (B). Gradient elution started from $15 \%$ (B), followed by a linear gradient to $85 \%$ (B) over $0.6 \mathrm{~min}$ and held for another $0.6 \mathrm{~min}$ then zoomed to $15 \%$ (B) in the next $0.1 \mathrm{~min}$, and finally re-equilibrated to $15 \%$ (B) in $0.9 \mathrm{~min}$. MS detection was performed in a positive ESI mode with the source temperature at $550{ }^{\circ} \mathrm{C}$ and ion spray voltage at $5.5 \mathrm{kV}$.

\section{In vivo PK studies}

\section{Procedure}

Animals utilized for preclinical studies include nude mice, rats and dogs. All animals were treated in accordance with Institutional Guide for the Care and Use of Laboratory Animals. Nude mice (around 20g, 9 males and 9 females) were purchased from Sino-British Sippr/BK Lab Animal Co. Ltd (Shanghai) (SCXK 2013-0016), Sprague Dawley (SD) rats (200-250g, 3 males and 3 females) from Shanghai SLAC Laboratory Animal Co., LTD (SYXK 2003-0029), and beagle dogs (9-13kg, 2 males and 2 females) from Beijing Marshall Biotechnology Co., Ltd (SCXK 2009-0002), respectively. Briefly, test compounds were administrated in both intravenous (i.v.) and intragastric (i.g.) for mice, rats and dogs in order to obtain their bioavailability. Plasma samples of nude mice, SD rats and dogs were collected at pre-dose and $0.083,0.25,0.5,1,2,4,6,8,12,24 \mathrm{~h}$ after the IV administration, plasma samples of SD rats were collected at pre-dose and 1.0, 2.0, 3.0, 3.5, 4, 4.5, 5, 6, 8, 12, $24 \mathrm{~h}$ and plasma samples of beagle dogs were collected at pre-dose and $0.5,1.0,1.5,2,2.5,3,4,6,8,12,24 \mathrm{~h}$ after the i.g. dose.

\section{Formulation}

Unless otherwise noted, 5\% DMSO+95\% (10 solutol HS-15) was generally used as standard formulation for IV and PO in rat and mouse PK studies. The formulation for compound 9 (Table 2, ig @ 2mpk, iv @ 1mpk) was 5\%DMA+40\%PEG400+55\%(10\%TPGS solution) . In dog PK study (Table 7, ig @ 2/20 mpk, iv @ 1 mpk), the formulation of SHR1653 was 2\%DMSO+98\%(HP- $\beta-C D)$.

\section{In Vitro Experiments}

\section{Generation of human $O T R, V_{1 A} R, V_{1 B} R$ and $V_{2} R$-expressing HEK293 cells}

The pcDNA3.1 plasmids containing human OTR, $\mathrm{V}_{1 \mathrm{~A}} \mathrm{R}, \mathrm{V}_{1 \mathrm{~B}} \mathrm{R}$ and $\mathrm{V}_{2} \mathrm{R}$ cDNA were synthesised by GENEWIZ (Suzhou, China) and HEK293 Cells were transfected with pcDNA3.1-hOTR, pcDNA3.1- 
$\mathrm{hV}_{1 \mathrm{~A}} \mathrm{R}$, pcDNA3.1-hV $\mathrm{B}_{\mathrm{B}} \mathrm{R}$ or pcDNA3.1-hV $\mathrm{V}_{2} \mathrm{R}$ by using Lipofectamine ${ }^{\circledR} 3000$ Transfection kit(Life Technologies, USA), and were maintained in MEM(Hyclone, USA) supplemented with 10\% Fetal Bovine Serum(FBS) (GIBCO, US) at $37^{\circ} \mathrm{C}$ and $5 \% \mathrm{CO}$. Selection of receptor-positive clones was achieved by treatment with antibiotic G418 (Enzo, USA) for 7-14 days. Stably transfected cell lines (HEK293/hOTR, HEK293/hV ${ }_{1 \mathrm{~A}} \mathrm{R}$, HEK293/hV $\mathrm{H}_{1 \mathrm{~B}} \mathrm{R}$ and $\mathrm{HEK} 293 / \mathrm{hV}_{2} \mathrm{R}$ ) were subsequently maintained in MEM containing 10\% FBS and G418.

IX-01 was included as a positive control of each batch. The potency of IX-01 was consistent and the average OTR IC50 $=23 \mathrm{nM}$.

\section{Calcium Assay}

Calcium flux was measured using Fluo-4 NW Calcium Assay Kits (Invitrogen, USA) according to manufacturer's instruction. Briefly, HEK293/hOTR, HEK293/hV ${ }_{1 \mathrm{~A}} \mathrm{R}$ or HEK293/hV ${ }_{1 \mathrm{~B}} \mathrm{R}$ cells were seeded into a 96 well plate at a concentration of $2.5 \times 10^{4}$ cells/well for culture at $37^{\circ} \mathrm{C}$ and $5 \% \mathrm{CO} 2$ for 24 hour, and then the culture medium was discarded and $100 \mathrm{uL}$ loading buffer containing Fluo-4 dye was added into each well for $30 \mathrm{~min}$ incubation at $37^{\circ} \mathrm{C}$. The cells were put at room temperature for $15 \mathrm{~min}$, and then treated with test compounds for $10 \mathrm{~min}$ at room temperature. Vasopressin (Tocris, UK) was added automatically and the signal was detected immediately at EX495/EM516 nM for 2 min on Flexstation 3 microplate reader (Molecular Devices, USA).

\section{cAMP Assay}

cAMP level were measured using cAMP dynamic 2 kit (Cisbio, USA) according to manufacturer's instruction. Briefly, HEK293/hV 2 R cells were collected and suspended in culture medium at a final concentration of $2.5 \times 10^{5} / \mathrm{mL}$, and then seed into 384 well plates (5uL/well). Cells were treated with test compounds at room temperature for 30 minutes, and then vasopressin (Tocris, UK) was added into each well and incubated at room temperature for additional $30 \mathrm{~min}$. cAMP signal was read by PheraStar(BMG Labtech, German ).

\section{Method for in vivo efficacy}

\section{Uterine Contraction Model}

Oxytocin-induced uterine contractions were performed according to Cirillo et al. (2003). ${ }^{4}$ Virgin female Sprague Dawley rats (240 to 260 grams, from JSJ-lab, Shanghai, China) were used in this study. After arrival, the rats were allowed to acclimate to the facility for at least one week. The rats were housed in room with controlled temperature $\left(20\right.$ to $\left.26^{\circ} \mathrm{C}\right)$, humidity $(30 \%-70 \%)$ and light cycles (12 hours light and 12 hours dark) with lights on at $8 \mathrm{am}$. The rats were given ad libitum access to food and water. All procedures were performed in accordance with the requirements of Institution Animal Care and Use Committee at Shanghai Hengrui.

The rats were randomized to different treatment groups by body weight. On the day of experiment, they were given vehicle solution (45\% Cremophor RH40, 18\% Masine 35-1, 27\% PEG400, 10\% ethanol) or designated compound solution by oral gavage $(6 \mathrm{~mL} / \mathrm{kg}) .20$ minutes after dosing, they were anesthetized with urethane $(20 \%, 9 \mathrm{ml} / \mathrm{kg}$, i.p. injection). The jugular vein was cannulated with PE tubing for i.v. dosing. A midline incision was made at the hypogastrium level, to expose the left uterine horn. 
The distal end (near the ovary) of the horn was ligated with surgical suture. One incision was made at the uterine horn wall, about $3 \mathrm{~cm}$ posterior to the first tie, close to the uterus body. A PE tubing was inserted into the uterine lumen and secured with surgical suture. The uterine cavity was filled with about $0.1 \mathrm{ml}$ sterile saline solution. The catheter was connected to pressure transducer (YPJ01H, Chengdu instrument factory, Chengdu, China), then to the multi-function signal conversion/recording system (RM6240C, Chengdu instrument factory, Chengdu, China). After the pressure reading was stabilized, 1 $\mu \mathrm{g} / \mathrm{kg}$ oxytocin was dosed intravenously exactly one hour after vehicle or compound oral dosing. The intraluminal uterine pressure was recorded for 15 to 30 minutes.

The contractile response was calculated by the ratio of AUC changes in intraluminal uterine pressure, to the baseline AUC. The baseline $\mathrm{AUC}_{0}$ was the 5 minute's area under the pressure curve prior to oxytocin dosing. The $\mathrm{AUC}_{\mathrm{T}}$ was the 5 minute's area under the pressure curve right after oxytocin dosing. The change of the baseline AUC ratio ( $\delta \mathrm{AUC}$ ratio) was calculated as below.

$\delta \mathrm{AUC}$ ratio $=\left(\mathrm{AUC}_{\mathrm{T}}-\mathrm{AUC}_{0}\right) / \mathrm{AUC}_{0}$

\section{References}

1. Brown, A.; Brown, T. B.; Calabrese, A.; Ellis, D.; Puhalo, N.; Ralph, M.; Watson, L. Bioorganic and Medicinal Chemistry Letters, 2010, 20, 516 - 520.

2. Xu, F.; Murry, J. A.; Simmons, B.; Corley, E.; Fitch, K.; Karady, S.; Tschaen, D. Org. Lett. 2006, 8, 3885-3888.

3. Zhu, J.; Han, L.; Diao, Y.; Ren, X.; Xu, M.; Xu, L.; Li, S.; Li, Q.; Dong, D.; Huang, J.; Liu, X.; Zhao , Z.; Wang, R.; Zhu, L.; Xu, Y.; Qian, X.; Li, H. Journal of Medicinal Chemistry, 2015, 58, 1123-1139

4. Cirillo, R.;Tos, E. G.; Schwarz, M. K.; Quattropani, A.; Scheer, A.; Missotten, M.; Dorbais, J.; Nichols, A.; Borrelli, F.; Giachetti, C.;Golzio, L.;Marinelli, P.;Thomas, R.J.; Chevillard, C.; Laurent, F.; Portet, K.; Barberis, C.; Chollet, A. J. Pharmacol. Exp. Ther. 2003, 1, 253-261. 